\title{
Extending the Community Multiscale Air Quality (CMAQ) modeling system to hemispheric scales: overview of process considerations and initial applications
}

\author{
Rohit Mathur $^{1}$, Jia Xing ${ }^{1,2}$, Robert Gilliam ${ }^{1}$, Golam Sarwar ${ }^{1}$, Christian Hogrefe ${ }^{1}$, Jonathan Pleim ${ }^{1}$, George Pouliot ${ }^{1}$, \\ Shawn Roselle ${ }^{1}$, Tanya L. Spero ${ }^{1}$, David C. Wong ${ }^{1}$, and Jeffrey Young ${ }^{1}$ \\ ${ }^{1}$ National Exposure Research Laboratory, Office of Research and Development, US Environmental Protection Agency, \\ Research Triangle Park, NC, USA \\ ${ }^{2}$ School of Environment, Tsinghua University, Beijing, 100084, China \\ Correspondence to: Rohit Mathur (mathur.rohit@epa.gov)
}

Received: 7 April 2017 - Discussion started: 4 May 2017

Revised: 10 August 2017 - Accepted: 31 August 2017 - Published: 19 October 2017

\begin{abstract}
The Community Multiscale Air Quality (CMAQ) modeling system is extended to simulate ozone, particulate matter, and related precursor distributions throughout the Northern Hemisphere. Modeled processes were examined and enhanced to suitably represent the extended space and timescales for such applications. Hemispheric-scale simulations with CMAQ and the Weather Research and Forecasting (WRF) model are performed for multiple years. Model capabilities for a range of applications including episodic longrange pollutant transport, long-term trends in air pollution across the Northern Hemisphere, and air pollution-climate interactions are evaluated through detailed comparison with available surface, aloft, and remotely sensed observations. The expansion of CMAQ to simulate the hemispheric scales provides a framework to examine interactions between atmospheric processes occurring on various spatial and temporal scales with physical, chemical, and dynamical consistency.
\end{abstract}

\section{Introduction}

Comprehensive atmospheric chemistry transport models must constantly evolve to address the increasing complexity arising from emerging applications that treat multi-pollutant interactions on urban to hemispheric spatial scales and hourly to annual temporal scales. To assist with the design of emission control strategies that comply with more stringent air quality standards, such models must accurately simulate am- bient pollutant levels across the entire spectrum ranging from background to extreme concentrations. The adverse impacts of airborne pollutants are not confined to a region or even a continent (NRC, 2009). Both observational (e.g., Andrea et al., 1988; Fishman et al., 1991; Jaffe et al., 1999; Zhang et al., 2008; Uno et al., 2009) and modeling studies (e.g., Jacob et al., 1999; Fiore et al., 2009; HTAP, 2010) have demonstrated that pollutants near the Earth's surface can be convectively lofted to higher altitudes where strong winds can efficiently transport them from one continent to another, thereby impacting air quality on intercontinental to global scales.

As air quality standards are tightened, the need to quantify the contributions of long-range transport to local pollution becomes increasingly important. Limited-area models such as the Community Multiscale Air Quality (CMAQ) (Byun and Schere, 2006; Foley et al., 2010; Appel et al., 2017) have played a central role in guiding the development and implementation of the National Ambient Air Quality Standards (NAAQS). These models are now being routinely applied to examine variability in surface-level air pollutants across the continental United States over annual cycles. Since transport is efficient in the free troposphere (FT) and since simulations over continental scales and annual cycles provide sufficient opportunity for "atmospheric turnover", i.e., exchange between the FT and the boundary layer (BL), it can be argued that accurate simulation of the variability in free-tropospheric pollutant concentrations is important for the model's ability to capture the variability in surfacelevel concentrations, especially at moderate to low concen- 
trations. Based on typical advective timescales, it can further be postulated that in limited-area chemistry transport models, this free-tropospheric variability in simulated concentrations is largely dictated by the specification of lateral boundary conditions (LBCs). This is exemplified in Fig. 1, which illustrates the influence of LBC specification on simulated surface-level concentrations across a typical regional modeling domain covering the contiguous United States; the spaceand time-varying LBCs themselves were derived from the global Integrated Forecasting System of the European Center for Medium-Range Weather Forecasts (ECMWF) (Flemming et al., 2015). In these calculations, three tracer species were added to CMAQ to track the ozone $\left(\mathrm{O}_{3}\right)$ LBC specified for three vertical zones: (i) surface to $750 \mathrm{hPa}$, nominally representing the atmospheric BL, (ii) 750-250 $\mathrm{hPa}$ representing the FT, and (iii) $250-50 \mathrm{hPa}$ (the model top) representing possible stratospheric influences (see Mathur et al., 2008). These tracer species were subject to transport processes associated with 3-D advection, turbulent mixing in the vertical and horizontal diffusion, and cloud transport on resolved and sub-grid scales. The tracer species were deposited at the surface using space- and time-varying deposition velocity estimates for $\mathrm{O}_{3}$, and they were also subjected to wet scavenging and rainout processes that mimic modeled $\mathrm{O}_{3}$. If the tracer background is defined as the amount of the tracer imported into the regional domain, then the sum of the three simulated tracers can be viewed as the modeled background for this species. Since we did not include chemical sinks for the tracers and since the intent here is to assess the relative influence of LBC, we examine the distribution of the normalized concentrations (normalized by the domain maximum value across all seasons) in Fig. 1a-d. Significant spatial and seasonal variability is seen in the estimated tracer background levels, with higher normalized concentration values in the high-elevation regions of the intermountain west. Additionally, higher background levels are estimated in the warmer seasons, with the highest levels during spring. More importantly, the free-tropospheric concentrations dominate the surface background levels (Fig. 1e-h). During summer, across most of the continental United States more than half (and up to $90 \%$ ) of the tracer background originated in the FT. Though significant seasonal variability is noted in the FT fractional contributions to surface-level background concentrations, the contributions are still substantial during other seasons and expectedly the highest contributions are seen in the high-elevation regions of the western United States across all seasons. These results clearly illustrate the importance of accurately characterizing the long-range transport that occurs in the FT and its influence on surface background pollution levels via subsidence and entrainment into the BL. It can be expected that pollutants with atmospheric lifetimes greater than a few days would exhibit similar characteristics, thereby highlighting the need to accurately characterize long-range transport influences on regional model simulations spanning seasonal to annual timescales.

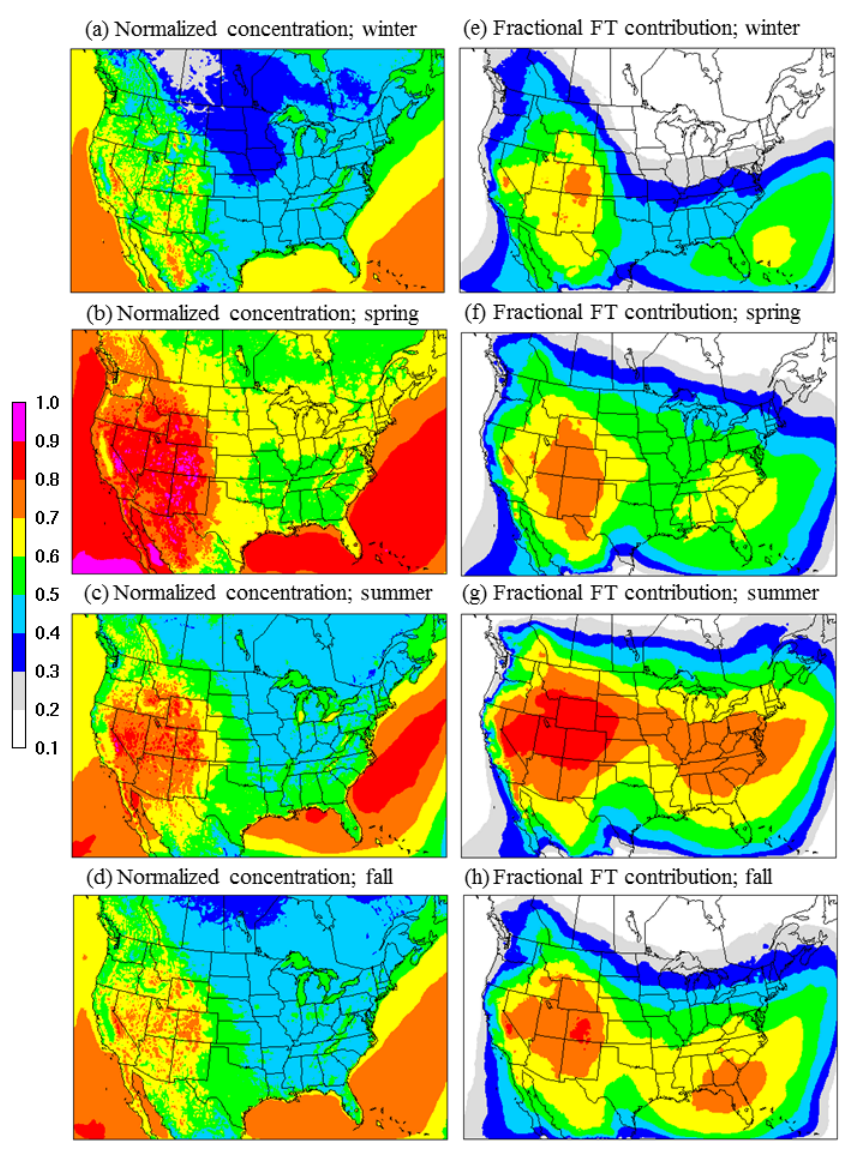

Figure 1. Impact of lateral boundary conditions (LBCs) on simulated seasonal surface-level concentrations. (a-d) Spatial variation in seasonal-mean surface concentrations normalized by the maximum value within the model domain across all seasons. (e-h) Fractional contribution of free-tropospheric (FT) LBCs (specified between 750 and $250 \mathrm{hPa}$ ) to the total LBC-derived concentrations at the surface. Seasons are defined as winter (December-February), spring (March-May), summer (June-August), and fall (SeptemberNovember).

One approach to capturing the effects of long-range transport in regional models is through deriving space- and timevarying LBCs from global chemistry transport models. However, efforts linking regional- and global-scale models have met with mixed success because biases in the global model can propagate and influence regional calculations and often confound interpretation of model results (e.g., Tang et al., 2008; Schere et al., 2012). Additionally, inconsistencies in process representations, species mapping, and grid structures could also introduce errors in the model linkage if not examined and handled carefully. A modeling framework is thus needed wherein interactions between processes occurring on various spatial and temporal scales can be consistently examined. Expanding comprehensive regional models to the hemispheric scale enables a consistent representation of atmospheric processes across spatial and temporal scales. Mo- 
tivated by this need, the applicability of the CMAQ modeling system has been extended to hemispheric scales through systematic investigation of key model processes and attributes influencing simulated distributions of $\mathrm{O}_{3}$, fine particulate matter $\left(\mathrm{PM}_{2.5}\right)$, and precursor species. The hemispheric modeling system also facilitates the examination of linked air pollution-climate across a region in the context of the changing global atmosphere.

Section 2 overviews the key CMAQ model structural attributes and process representations that were refined to fully simulate the Northern Hemisphere. Section 3 summarizes a variety of applications with the hemispheric CMAQ configuration, highlights the model performance relative to a variety of observational data sets, and identifies aspects that would benefit from further model development. A variety of surface, aloft, and remotely sensed observations used to guide and evaluate the model changes are presented in Sects. 2 and 3. Lastly, Sect. 4 summarizes the current model state and discusses future development and applications of the hemispheric CMAQ.

\section{Model setup and process enhancements}

Atmospheric chemistry and transport of trace species occur across the continuum of spatial and temporal scales. For instance, transport across intercontinental to hemispheric scales occurs over timescales ranging from days to months, which influences the distribution of trace species with lifetimes within this range. Transport on these scales can also influence shorter-lived radical budgets through chemical reactions involving intermediate-lived species, especially reservoir species such as organic nitrates. Thus, the expansion of CMAQ to hemispheric scales required reexamination of process representations and grid structures so that interactions amongst various processes occurring over the disparate scales is adequately captured. The key changes to CMAQ that were considered in this effort are summarized below.

\subsection{Domain and grid configuration}

CMAQ's governing three-dimensional equations for species mass conservation and moment dynamics (number, surface area, and volume) describing modes of particulate size distribution are cast in generalized coordinates (see Mathur et al., 2005; Byun and Schere, 2006). This formulation allows CMAQ to accommodate horizontal map projections and vertical coordinates from various meteorological models. This flexibility enables CMAQ to be used on a horizontal domain covering the Northern Hemisphere set on a polar stereographic projection (Fig. 2a) without altering CMAQ or its input-output file structure. Polar stereographic projections are also used in the Danish Eulerian Hemispheric Model (Brandt et al., 2012) and a hemispheric version of the CHIMERE model (Mailler et al., 2017). Current WRF and
CMAQ hemispheric applications have utilized a horizontal discretization of a $187 \times 187$ grid configuration with a grid spacing of $108 \mathrm{~km}$ and terrain-following $\sigma$ vertical coordinate vertical coordinate system. Current regional modeling applications with CMAQ typically utilize 35 layers of variable thickness to resolve the model vertical extent between the surface and $50 \mathrm{hPa}$. Longer-term calculations over the Northern Hemisphere must be able to capture potential impacts of stratosphere-troposphere exchange (STE) as well as that between the FT and the BL. At altitudes above $10 \mathrm{~km}$ (Fig. 2b), the 35-layer configuration has relatively coarse resolution with layer thickness $>1.5 \mathrm{~km}$ and the topmost layer is nearly $4 \mathrm{~km}$ deep. To improve the representation of threedimensional transport processes on modeled vertical profiles, the vertical resolution employed in hemispheric CMAQ calculations is increased. The revised layer structure uses 44 layers, with significantly finer resolution above the BL (Fig. 2b) to better represent long-range transport in the FT, STE processes, and influences from cloud mixing on both the sub-grid and resolved scales. The impacts of using these alternate layer configurations are illustrated in Fig. 3 for a case in which only emissions across the United States were zeroed out to isolate the impacts of model vertical resolution on representing the downward transport of pollutants in the region. Both the 35-layer and 44-layer model simulations were initialized with the same conditions in mid-February 2006, utilized a constant potential vorticity (PV) scaling to specify $\mathrm{O}_{3}$ in the model top layer (discussed further in Sect. 2.5), and were driven by meteorological information from the Weather Research and Forecasting (WRF) model simulations using the respective layer configurations (discussed in Sect. 2.2). Figure 3 shows systematically higher simulated $\mathrm{O}_{3}$ below $10 \mathrm{~km}$ in the 35-layer configuration compared to the 44-layer configuration, indicating that the coarser vertical resolution will likely overestimate the downward transport of both longrange transport effects as well as stratospheric influences.

\subsection{Coupling of WRF and CMAQ and initialization}

To minimize interpolation error and to avoid introducing mass imbalances, hemispheric simulations with CMAQ inherit the projection and grid structure from the WRF model, which provides the driving meteorological fields. In applications presented in Sect. 3, meteorological inputs for grid nudging used in WRF over the Northern Hemisphere domain were derived from the NCEP/NCAR Reanalysis data (Kalnay et al., 1996), which have $2.5^{\circ}$ spatial and $6 \mathrm{~h}$ temporal resolution; other reanalysis products such as Global Forecast System (GFS) can also be used instead. Surface reanalysis based on a fusion of the NCEP/NCAR Reanalysis and NCEP Automated Data Processing (ADP) Operational Global Surface Observations on the WRF grid using the NCAR distributed objective analysis tool OBSGRID (http://www2.mmm.ucar.edu/wrf/users/docs/user_ guide_V3.1/users_guide_chap7.htm\#techniques) is used for 

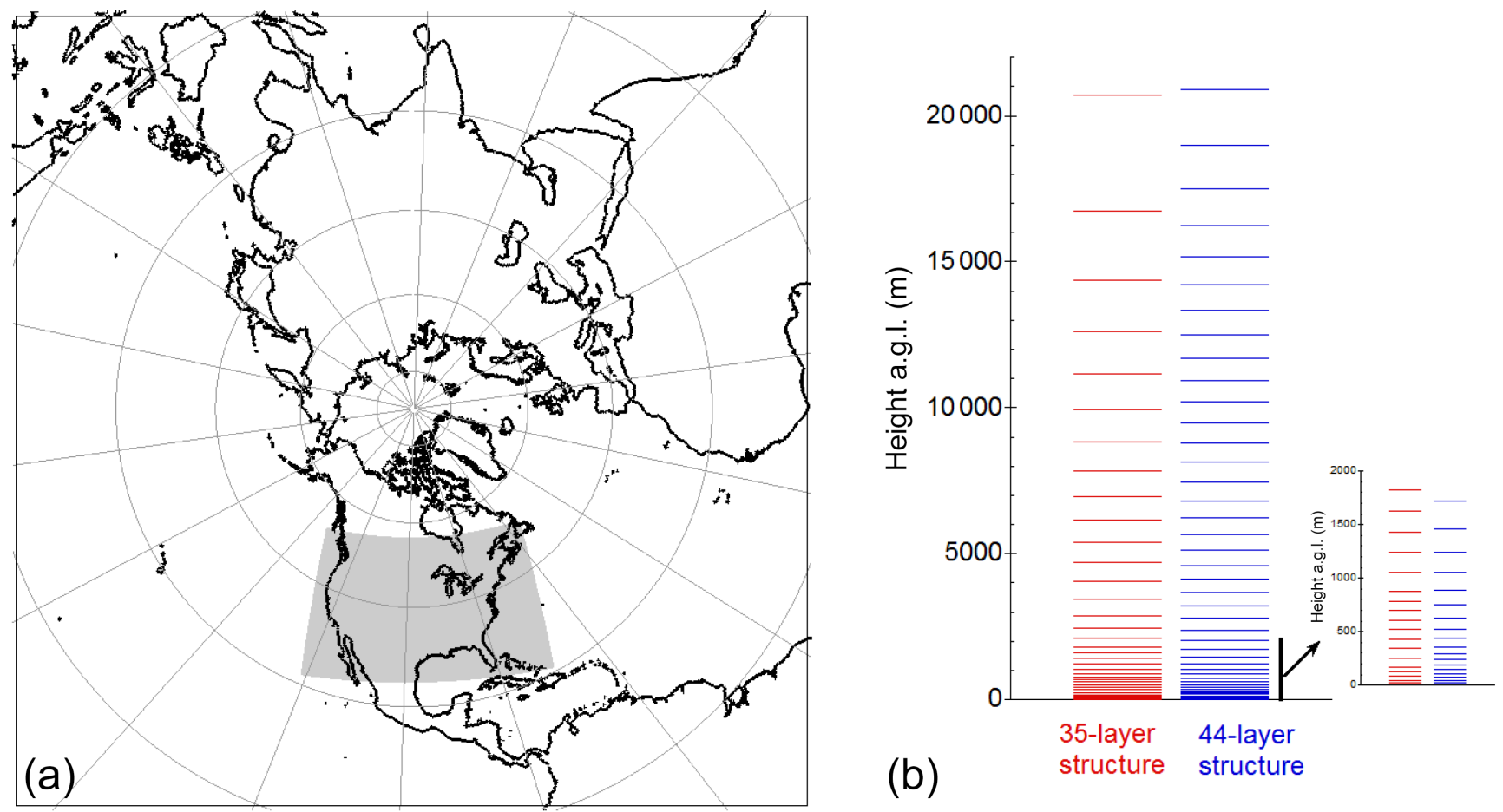

Figure 2. (a) The Northern Hemisphere modeling domain discretized using a $108 \mathrm{~km}$ resolution grid. The shaded region shows the extent of the typical continental US nested domain discretized using a $12 \mathrm{~km}$ resolution horizontal grid. (b) Comparison of two layer configurations used to discretize the vertical extent ranging from the surface to $50 \mathrm{hPa}$.
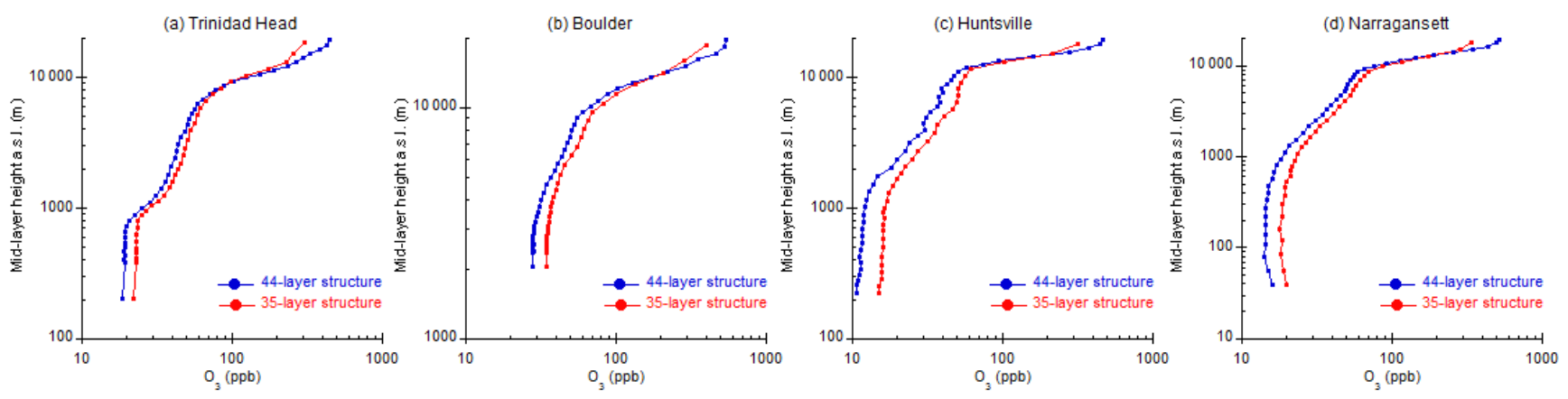

Figure 3. Impact of layer configuration on simulated mean $\mathrm{O}_{3}$ vertical profiles for August 2006 at selected locations for a case involving zero-out of emissions across the United States: (a) Trinidad Head, CA; (b) Boulder, CO; (c) Huntsville, AL; and (d) Narragansett, RI.

the indirect soil moisture and temperature nudging in the Pleim-Xiu land surface model (Pleim and Gilliam, 2009). The WRF configuration over the Northern Hemisphere also used MODIS land use classification with 20 categories, RRTMG shortwave radiation (SWR) and longwave radiation schemes (Iacono et al., 2008), and the ACM2 planetary BL model (Pleim, 2007). WRF's simulation of hourly surface temperature, relative humidity, and wind speed and direction was evaluated by Xing et al. (2015a) through comparison with observations from NOAA's National Centers for Environmental Information (NCEI) Integrated Surface Data and no significant bias in the meteorological fields was detected.
WRF and CMAQ can be run either in the traditional off-line sequential manner or in the coupled mode with or without aerosol feedback effects (Mathur et al., 2010; Wong et al., 2012).

Expectedly, the application over expanded space and timescales necessitates closer attention to model chemical initialization, especially in the FT wherein typical residence times for most atmospheric pollutants of concern are long enough so that initial conditions can persist. If the FT is poorly represented, model predictions within the BL will be adversely affected. Thus, unlike regional simulations with CMAQ, which are initialized with a prescribed vertical pro- 
(a) March 2006

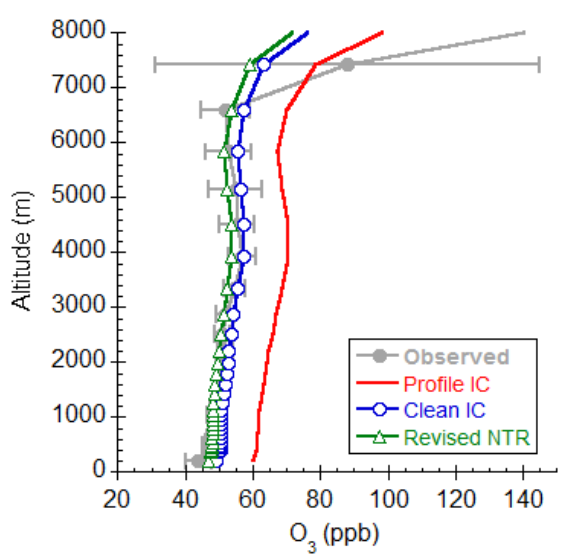

(b) August 2006

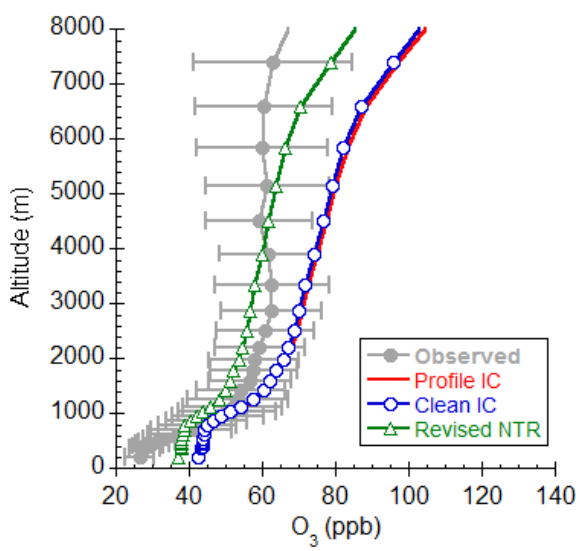

Figure 4. Comparisons of simulated average vertical profiles of $\mathrm{O}_{3}$ with ozonesonde measurements at Trinidad Head, California, USA: (a) March 2006 (4 months after start of simulation) and (b) August 2006 (9 months after start of simulation). Also shown is \pm 1 SD of the observed mixing ratios. "Profile IC" uses the default profile for initialization as in regional CMAQ applications, "Clean IC" is the case in which the model is spun up from clean conditions, and "Revised NTR" is the simulation with "Clean IC" with updates to the physical and chemical sinks for the species NTR representing organic nitrates.

file for different species or with concentration fields derived from global chemistry transport models, for hemispheric applications it is recommended that CMAQ be initialized to "clean" tropospheric background values and allowed to build up based on the model emissions, physics, and chemistry. The impact of these different initializations is illustrated through comparisons of the cases denoted Profile IC and Clean IC in Fig. 4, which compares monthly mean model and observed $\mathrm{O}_{3}$ profiles at Trinidad Head, CA. In the Profile IC case, a vertical $\mathrm{O}_{3}$ profile that monotonically increased from $35 \mathrm{ppb}$ at the surface to $100 \mathrm{ppb}$ at model top was used for initialization. The clean IC case initialized $\mathrm{O}_{3}$ at $30 \mathrm{ppb}$ through the model column. In both cases, the hemispheric model simulations were initiated on 1 November 2015. Initial conditions for all other chemical species were based on clean tropospheric conditions prescribed in Byun and Ching (1999). Large overestimations in $\mathrm{O}_{3}$ through the troposphere are noted for the Profile IC simulation and arise from the profile used to initialize $\mathrm{O}_{3}$ in the mid-troposphere. In contrast, the Clean IC case, wherein the model was initialized to clean tropospheric background values and allowed to build up based on the model physics and chemistry, resulted in much better agreement with the measured profile during spring (Fig. 4a); however, by summer, overestimations developed (discussed further in Sect. 2.4.1). Note that the Clean IC case also utilized a fixed PV scaling for $\mathrm{O}_{3}$ at the model top, described further in Sect. 2.5. Also, the similarity in simulated $\mathrm{O}_{3}$ profiles for the Clean IC and Profile IC cases by August, 9 months after the start of the simulation, suggests the diminishing impact of initialization. Based on these results, the inherent seasonality in atmospheric transport and chemistry, and practices employed in previous global chem- istry transport model applications (e.g., Fiore et al., 2009), a spin-up of 12 months from clean tropospheric conditions is recommended for new CMAQ applications over the Northern Hemisphere. Additional future studies would be helpful to further constrain this spin-up period recommendation.

Similar to regional applications, chemical boundary conditions also need to be specified along the discrete lateral boundaries of the hemispheric domain. In current applications, these are set to the same values as in the Clean IC case discussed above. Note that the boundaries of the hemispheric domain (shown in Fig. 2) are in the area encircling the Earth near the Equator. Because of the presence of the intertropical convergence zone in this region, the mixing of air masses originating in the Northern and Southern hemispheres occurs relatively slowly, with exchange times of typically about 1 year (e.g., Jacob et al., 1987). Since the atmospheric lifetimes of most modeled species are significantly shorter, any impacts of chemical lateral boundary condition specification are typically confined to the lower latitudes and do not propagate into the domain. Additional model sensitivity tests should however be conducted in the future to quantify any likely seasonal influence of LBC specification on model predictions in lower-latitude regions of the Northern Hemisphere.

\subsection{Emissions}

Specifying emissions across the Northern Hemisphere is challenging because the distributions and compositions of emissions across the globe are rapidly changing and because emissions are poorly quantified in many regions. In addition, simulations of CMAQ on broader spatial scales are influenced by emissions from marine environments (which are 
less prominent in regional and continental applications) and intercontinental transport of other sources (e.g., windblown dust). Changes to emissions used by CMAQ for the Northern Hemisphere application are described below.

\subsubsection{Global emission inventories}

Two primary sources of global emission estimates have been used in hemispheric CMAQ applications to date. The first is based on a global emission inventory compiled by Argonne National Laboratory in support of the ARCTAS pre-mission planning and includes estimates for anthropogenic, international shipping, and biomass burning (http://bio.cgrer.uiowa. edu/arctas/emission.html). This inventory was used in early testing of the hemispheric CMAQ model (e.g., Mathur et al., 2014) and will be referred to as the ARCTAS inventory in subsequent discussions. More recent applications have relied on year-specific estimates from the EDGAR (Emission Database for Global Atmospheric Research, version 4.2; European Commission, 2011) database, which reports emissions for 17 anthropogenic sectors and large-scale biomass burning on a $0.1^{\circ} \times 0.1^{\circ}$ resolution grid. Since EDGARv4.2 provides only $\mathrm{PM}_{10}$ emissions, $\mathrm{PM}_{2.5}$ emissions were estimated by deriving the ratio of $\mathrm{PM}_{2.5}$ to $\mathrm{PM}_{10}$ from the 20002005 EDGAR HTAP (Hemispheric Transport of Air Pollution, version 1) inventory (Janssens-Maenhout et al., 2012) and then applying this ratio to partition EDGARv4.2 $\mathrm{PM}_{10}$ emissions into $\mathrm{PM}_{2.5}$ and $\mathrm{PM}_{2.5-10}$ (Xing et al., 2015a). In applications to date, biogenic volatile organic compound (VOC; Guenther et al., 1995) and lightning $\mathrm{NO}_{x}$ (Price et al., 1997) emissions were obtained from GEIA (Global Emissions Inventory Activity; http://www.geiacenter.org). The monthly biogenic VOC emissions were further temporalized to hourly resolution for each simulation day. Monthly lightning $\mathrm{NO}_{x}$ emissions were distributed evenly to each hour of each simulation day. Xing et al. (2015a) further describe the processing of global emission inventories for CMAQ, including temporalization of the annual estimates to hourly model inputs, vertical distributions of anthropogenic and lightning emissions, and speciation of $\mathrm{PM}_{2.5}$ and nonmethane volatile organic compound emissions to model primary aerosol constituents and gas-phase species. Emissions of $\mathrm{NO}$ from soil or $\mathrm{SO}_{2}$ from volcanos are not considered in the applications presented here. It should also be noted that several efforts are underway to harmonize regional emission estimates and incorporate them into global emission inventories with improved spatial and temporal resolution (e.g., Janssens-Maenhout et al., 2015). Furthermore, the SMOKE modeling system typically used to prepare emissions for regional CMAQ applications has recently been updated to support hemispheric CMAQ applications to allow for a more streamlined implementation of the various emission processing steps described above (Eyth et al., 2016).

\subsubsection{Windblown dust}

The windblown dust emission parameterization employed in CMAQ (Tong et al., 2008) was adapted for hemispheric applications by making two primary modifications. First, the mapping for land use categories representing potentially erodible dust sources was updated to map the categories of the MODIS land use types used in the hemispheric WRF-CMAQ configuration. Second, the threshold friction velocity (above which dust emissions occur due to wind action) for desert regions was reduced to mobilize sufficient episodic dust emissions over the Sahara. The original value for threshold friction velocity, derived from the work of Gillette et al. (1980), was based on data from the Mojave Desert. However, Li et al. (2007) suggest a much lower (about half) threshold friction velocity based on dust samples from the northern China desert. Fu et al. (2014) found that the default threshold friction velocity for loose, fine-grained soil with low surface roughness was too high for Asian dust sources and that reducing it to the $\mathrm{Li}$ et al. (2007) values yielded much better agreement of simulated airborne dust relative to observations. We found similar underestimations in $\mathrm{PM}_{2.5}$ concentrations and aerosol optical depth (AOD) over the Sahara with the default values and have thus followed an approach similar to Fu et al. (2014) in the hemispheric CMAQ applications presented here. Concurrent with the development of this paper, a newer physics-based windblown dust emission parameterization was developed and implemented in CMAQ, and that parameterization includes a dynamic relation for the surface roughness length relevant to small-scale dust generation processes (Foroutan et al., 2017). The new dust emission parameterization is currently being tested for hemispheric applications and will be available in future public releases of CMAQ.

\subsubsection{Emissions in marine environments}

Natural emissions of particulate matter and gas-phase species from the oceans can impact air quality in coastal regions, influence global burdens of atmospheric trace species and radiative budgets, and modulate lifetimes of tropospheric $\mathrm{O}_{3}$ thereby influencing its long-range transport. A detailed representation of sea-spray particle emissions and chemistry is already available in CMAQ (Kelly et al., 2010), and it can be used for hemispheric-scale applications without any modifications.

Reactive halogen emissions can play an important role in dictating lifetimes of $\mathrm{O}_{3}$ in marine environments. Parameterizations to estimate marine emissions of bromineand iodine-containing compounds for the three categories (halocarbons, inorganic bromine, and inorganic iodine) were developed for inclusion in the hemispheric CMAQ. The halocarbons include five bromocarbons $\left(\mathrm{CHBr}_{3}, \mathrm{CH}_{2} \mathrm{Br}_{2}\right.$, $\left.\mathrm{CH}_{2} \mathrm{BrCl}, \mathrm{CHBrCl}_{2}, \mathrm{CHBr}_{2} \mathrm{Cl}\right)$ and four iodocarbons $\left(\mathrm{CH}_{3} \mathrm{I}\right.$, $\mathrm{CH}_{2} \mathrm{ICl}, \mathrm{CH}_{2} \mathrm{IBr}, \mathrm{CH}_{2} \mathrm{I}_{2}$ ). The halocarbon emissions are esti- 
mated using monthly average climatological chl $a$ concentrations derived from the Moderate Resolution Imaging Spectroradiometer (MODIS). Sarwar et al. (2015) provide details on estimating halogen emission and comparisons with other existing estimates.

\subsection{Enhancements to gas-phase chemistry}

The 2005 Carbon Bond Mechanism with updated toluene chemistry (CB05TU; Sarwar et al., 2011), commonly used in regional CMAQ applications, was also used for initial hemispheric-scale applications. Important enhancements to CB05TU were implemented to improve (1) its ability to represent multi-day chemistry associated with cycling of $\mathrm{NO}_{x}$ through reservoir organic nitrate species in the mechanism and (2) representation of chemical sinks for tropospheric $\mathrm{O}_{3}$ due to halogen-mediated chemistry in marine environments. Additionally, the more detailed RACM2 mechanism has also been implemented (Sarwar et al., 2013) to facilitate its use in follow-on hemispheric applications.

\subsubsection{Organic nitrate lifetime}

Organic nitrates form during the atmospheric photodegradation of hydrocarbons in the presence of nitrogen oxides $\left(\mathrm{NO}_{x}\right)$ through reactions of peroxy-alkyl radicals $\left(\mathrm{RO}_{2}\right)$ with $\mathrm{NO}$ as well as through reactions with $\mathrm{NO}_{3}$, and they act as a reservoir for oxides of nitrogen. In the CB05TU mechanism, the species NTR is used to represent organic nitrates. Depending on its modeled lifetime, NTR can potentially redistribute $\mathrm{NO}_{x}$ from source regions to $\mathrm{NO}_{x}$-sensitive remote areas where additional ozone may be produced. Representing inert and reservoir organic nitrate species in condensed mechanisms used in chemistry transport models is challenging (e.g., Kasibhatla et al., 1997) since they can dramatically influence simulated $\mathrm{O}_{3}$ and $\mathrm{NO}_{y}$ distributions. In the CB05TU implementation in CMAQ, the chemical sinks for NTR include photolysis (producing $\mathrm{NO}_{2}$ ) and reaction with $\mathrm{OH}$ (producing $\mathrm{HNO}_{3}$ ). Additionally, defining a Henry's law constant for a single lumped species representing several alkyl nitrates such as NTR is challenging. In previous CMAQ versions, the Henry's law constant for peroxyacetyl nitrate (PAN) was also used for NTR, resulting in its very slow removal either through scavenging by clouds or through dry deposition at the Earth's surface. However, the Henry's law constants for several alkyl nitrates and hydroxyalkyl nitrates have been suggested to be much higher (some comparable to $\mathrm{HNO}_{3}$ ), especially those that are of biogenic origin (Shepson et al., 1996; Treves and Rudich, 2003). On the hemispheric scale, organic nitrates formed from isoprene are the largest contributor to the simulated tropospheric NTR burden and can consequently modulate the simulated tropospheric $\mathrm{O}_{3}$ burden. Based on recent work by Xie et al. (2013), we updated the rate constant for the NTR $+\mathrm{OH}$ reaction to that for isoprene nitrates. The Henry's law constant for NTR was also mapped to that of $\mathrm{HNO}_{3}$, thereby enhancing wet scavenging of NTR. Additionally, the dry deposition velocity for NTR was mapped to that for $\mathrm{HNO}_{3}$. Collectively, these changes result not only in faster $\mathrm{NO}_{x}$ recycling from NTR but also faster removal of NTR through the enhancement of its dry deposition and wet scavenging physical sinks.

The impacts of these changes to representing NTR in CMAQ on simulated $\mathrm{O}_{3}$ distributions are illustrated in Fig. 4, which presents a comparison of monthly mean profiles of simulated $\mathrm{O}_{3}$ mixing ratios for various cases with ozonesonde measurements at Trinidad Head, California, a site nominally representing inflow conditions to North America. The comparisons shown in Fig. 4 illustrate the relatively large effects of modulating the resultant NTR burden on the simulated $\mathrm{O}_{3}$ distribution through much of the lower to mid-troposphere, especially during summer when isoprene emissions are high. In limited-area calculations with the CB05TU mechanism, it is likely that the NTR produced is transported out of the regional domains before it can significantly alter $\mathrm{O}_{3}$ production. However, over the spatial and temporal scales of northern hemispheric calculations, $\mathrm{NO}_{x}$ recycled from NTR can modulate the simulated background $\mathrm{O}_{3}$; consequently, accurate characterization of its sources and sinks becomes critical. Thus, the hemispheric calculations provide a framework for examining the role of various physical and chemical processes in atmospheric chemical budgets in a consistent manner.

Additional improvements to representing NTR in the CB05TU mechanism in CMAQ are underway. In particular, replacing the single alkyl nitrate species (NTR) in CB05TU with seven species to better capture the range of chemical reactivity and Henry's law constants (and thus the physical sinks) is being investigated (Schwede et al., 2014; Appel et al., 2017). Early comparisons of this expanded treatment with the simpler changes discussed above suggest that the approximations invoked through mapping the $\mathrm{OH}$ reactivity to isoprene nitrates (from Xie et al., 2013) and mimicking NTR's wet and dry removal rates to $\mathrm{HNO}_{3}$, yield simulated $\mathrm{O}_{3}$ distributions similar to the ones obtained from the expanded treatment.

\subsubsection{Representation of marine environments}

More than half of the Northern Hemisphere is covered by oceans. To accurately represent the intercontinental transport of pollutants, it is important to accurately represent how continental air masses evolve as they traverse the vast oceanic regions. The fate of $\mathrm{O}_{3}$ in marine environments directly affects inflow to continental regions and background $\mathrm{O}_{3}$ concentrations. Though $\mathrm{O}_{3}$ photolysis in the presence of high water vapor results in chemical $\mathrm{O}_{3}$ loss and is well quantified, additional loss of $\mathrm{O}_{3}$ in these environments through deposition as well as chemical reactions with halogens emitted from the ocean is expected (Vogt et al., 1999; Read et al., 2008) but still uncertain and not represented in most 
tropospheric models. In expanding CMAQ to hemispheric scales, particular attention was devoted to the role of deposition and halogen chemistry in marine environments, which can serve as sinks for $\mathrm{O}_{3}$ exported from continental outflow and in transit to other regions via long-range transport. An enhanced $\mathrm{O}_{3}$ deposition treatment that accounts for the interaction of iodide in seawater with $\mathrm{O}_{3}$ was implemented (Sarwar et al., 2015) and found to increase deposition velocities in marine environments by an order of magnitude. In addition, the gas-phase chemical mechanisms were expanded to include 25 chemical reactions involving 7 chlorine species (Sarwar et al., 2012), 39 chemical reactions involving 14 bromine species, and 53 chemical reactions involving 17 iodine species (Sarwar et al., 2015).

\subsubsection{Alternate gas-phase mechanism}

As discussed in Sect. 2.4.1, characterizing multi-day chemistry and long-lived reservoir species is important for representing the long-range transport of pollutants and their distributions on hemispheric scales. To enable practical model applications over extended spatial and temporal scales, the chemical mechanisms must be sufficiently condensed to run efficiently while faithfully representing the chemistry over the space and timescales modeled. However, the impacts on model predictions of using different condensation rules and assumptions on species lumping and intermediate compounds are largely unquantified. To enable such investigation in the future over the hemispheric scale, an alternate chemical mechanism, RACM2 has also been implemented and tested in the hemispheric CMAQ (Sarwar et al., 2013). The RACM2 mechanism is designed to simulate remote to polluted conditions from the Earth's surface through the upper troposphere (Goliff et al., 2013). It consists of 363 chemical reactions including 33 photolytic reactions among 120 chemical species.

\subsection{Representing impacts of stratosphere-troposphere exchange on $\mathrm{O}_{3}$ distributions}

Though the role of cross-tropopause transport of $\mathrm{O}_{3}$ is acknowledged as a significant contributor to the tropospheric $\mathrm{O}_{3}$ budget, the distribution of $\mathrm{O}_{3}$ in the troposphere that originates from the stratosphere is still uncertain. Tightening $\mathrm{O}_{3}$ NAAQS and decreasing amounts of photochemically derived $\mathrm{O}_{3}$ due to continuously declining anthropogenic precursor emissions across large parts of North America and Europe now puts greater emphasis on accurately characterizing the fraction of $\mathrm{O}_{3}$ in the troposphere, especially at the surface, that is of stratospheric origin. For instance, Roelofs and Lelieveld (1997), using a global chemistry transport model, estimated that stratospheric contributions to surface $\mathrm{O}_{3}$ varied between 10 and $60 \%$ depending on season and location. Clearly this fraction varies spatially and seasonally in response to the tropopause height, and perhaps even more episodically, from deep intrusion events associated with weather patterns and frontal movement. PV has been shown to be a robust indicator of air mass exchange between the stratosphere and the troposphere, with strong positive correlation with $\mathrm{O}_{3}$ and other trace species transported from the stratosphere to the upper troposphere (Danielsen, 1968). Numerous modeling studies have used this correlation to develop scaling factors that specify $\mathrm{O}_{3}$ in the modeled upper troposphere-lower stratosphere (UTLS) based on estimated PV. The reported $\mathrm{O}_{3} / \mathrm{PV}$ ratios (e.g., Ebel et al., 1991; Carmichael et al., 1998; McCaffery et al., 2004), however, exhibit a wide range, $20-100 \mathrm{ppbPVu}^{-1}$ (1 PV unit $=$ $10^{-6} \mathrm{~m}^{2} \mathrm{~K} \mathrm{~kg}^{-1} \mathrm{~s}^{-1}$ ), and vary as a function of location, altitude, and season. Based on extensive ozonesonde measurements available during the summer of 2006 from the IONS network (http://croc.gsfc.nasa.gov/intexb/ions06.html) and PV fields from the WRF model matched to the location and time of the ozonesonde launch, we examined the UTLS $\mathrm{O}_{3}-$ PV correlation at sites across North America. At 12 sites with a sufficient number (11 or greater) of launches during August 2006, strong linear correlations $\left(r^{2}>0.7\right)$ were noted, with slopes of the linear regression varying between 20 and $39 \mathrm{ppbPVu}^{-1}$ (Mathur et al., 2008). Based on this analysis, in the initial implementation of STE impacts on tropospheric $\mathrm{O}_{3}$ in hemispheric CMAQ, we scale the space- and timevarying model-estimated $\mathrm{PV}$ in the topmost model layer with a scaling factor of $20 \mathrm{ppbPVu}^{-1}$ to specify $\mathrm{O}_{3}$ at the model top. This initial conservative choice for the $\mathrm{O}_{3} / \mathrm{PV}$ ratio was in part dictated by lack of additional information on seasonality and also by the relatively coarse model resolution in the UTLS. As indicated in Fig. 3, layer configuration influences the representation of STE and subsequent simulation of 3-D $\mathrm{O}_{3}$ distributions. Thus, the initial conservative choice of $20 \mathrm{ppbPVu}^{-1}$ was motivated by the desire to reduce any possible effects of excessive and artificial downward entrainment associated with inadequate vertical model resolution.

To overcome some of these challenges and to develop a more robust representation of STE impacts, we have recently developed a dynamic $\mathrm{O}_{3}-\mathrm{PV}$ function based on 21year ozonesonde records from the World Ozone and Ultraviolet Radiation Data Centre (WOUDC) with corresponding PV values from WRF-CMAQ simulation across the Northern Hemisphere from 1990 to 2010. Analyses of PV and ozonesonde data suggest strong spatial and seasonal variations in $\mathrm{O}_{3} / \mathrm{PV}$ ratios, which exhibit large values in the upper layers and in high-latitude regions, with the highest values in spring and the lowest values in autumn over an annual cycle. The new generalized parameterization, detailed in Xing et al. (2016a), can dynamically represent $\mathrm{O}_{3}$ in the UTLS across the Northern Hemisphere. The implementation of the new function significantly improves CMAQ's simulation of UTLS $\mathrm{O}_{3}$ in both magnitude and seasonality compared to observations, which results in a more accurate simulation of the vertical distribution of $\mathrm{O}_{3}$ across the Northern Hemisphere (Xing et al., 2016a). These hemispheric $\mathrm{O}_{3}$ 
fields can then be used to derive more realistic vertically and temporally varying LBCs for regional nested model calculations.

\section{Hemispheric-scale applications, analysis, and evaluation}

The hemispheric CMAQ model is now being used for a variety of process-based air pollution studies across the Northern Hemisphere over seasonal (e.g., Mathur et al., 2014; Sarwar et al., 2014) to decadal (Xing et al., 2015a) timescales. In this section we present an overview of these diverse evolving applications with the hemispheric CMAQ model. In some instances, the applications have been detailed before, but the analysis summarized here builds upon that previous work and those distinctions are stated in the individual application discussion. Detailed comparisons of model predictions of pollutant concentrations (and radiative properties) with corresponding observations are conducted to establish credibility in the model's use in these applications that range from representing episodic long-range pollutant transport to quantifying long-term trends in air pollution across the Northern Hemisphere, to emerging applications examining air pollution-climate interactions. Model applications are performed over the hemispheric domain and 44-layer structure illustrated in Fig. 2. The CMAQ configuration is based on version 5.0 (CMAQv5.0) with the process updates detailed in Sect. 2. Two sets of applications are analyzed and evaluated in the subsequent discussion: (1) a 21-year simulation over 1990-2010 (in Sect. 3.5 and 3.6) and (2) process sensitivity studies for the calendar year 2006, which were each initialized in September 2005 using fields from the prior 21-year simulation set (in Sect. 3.1-3.4).

\subsection{Comparing model predictions with measurements from the 2006 INTEX-B campaign}

The Intercontinental Chemical Transport Experiment-B (INTEX-B) was a NASA-led, multi-partner atmospheric field experiment conducted in the spring of 2006. A major objective of the second phase of the campaign during 17 April-15 May 2006 was characterizing the long-range transport and evolution of Asian pollution and implications for air quality across western North America (Singh et al., 2009). Airborne measurements of a variety of trace species were made over the remote Pacific as well as along the inflow region to western North America from aircrafts with extensive measurement instruments onboard and provide a unique data set to test and evaluate the ability of hemispheric CMAQ to represent the 3-D structure of air pollutants as they are transported long distances across the Pacific Ocean to eventually impact US background pollution levels.

The NASA DC-8 flights during 17 April-1 May 2006 were based out of Honolulu, Hawaii, and sampled the subtropi- cal Pacific, while the flights during 4-15 May 2006 based out of Anchorage, Alaska, sampled the troposphere over the subarctic Pacific region. Figure 5a-d present comparisons of modeled and observed $\mathrm{O}_{3}$ mixing ratios along selected flight paths of the DC- 8 aircraft; several of these flights were designed to sample aged and fresh Asian pollution over the Pacific (Table 5a in Singh et al., 2009). Modeled mixing ratios were extracted by flying the aircraft through the 3-D modeling domain; the spatial locations of the aircraft were mapped to the model grid, whereas hourly model output was temporally interpolated to the time of the measurement. Figure 5 shows results from three different CMAQ configurations aimed at isolating the impacts of STE and marine halogen chemistry on simulated 3-D $\mathrm{O}_{3}$ distributions. Differences between the simulations denoted "PV + Halogen" and "Halogen, NoPV" are used to estimate the $\mathrm{O}_{3}$ sources due to modeled STE processes, while differences between the simulations PV + Halogen and "PV, NoHalogen" help quantify the model $\mathrm{O}_{3}$ sinks due to halogen chemistry in marine environments. Note that the simulation PV, NoHalogen employed the CB05TU mechanism, while the other two simulations employed a version of the CB05TU mechanism augmented with the halogen chemistry discussed in Sect. 2.4.2. Comparisons of model predictions from the PV + Halogen simulation with observations along the various flight paths suggest that the model exhibits skill in capturing the vertical variations in $\mathrm{O}_{3}$ observed in the region. The simulation that did not employ any PV scaling (green trace in Fig. 5) systematically underestimates $\mathrm{O}_{3}$. The improved comparisons with measurements along the different flight paths for the $\mathrm{PV}+$ Halogen simulation suggest that $\mathrm{O}_{3}$ in the lower to mid-troposphere in this region during this period is often influenced by sizeable contributions from the stratosphere, and these enhancements are generally captured by the simulation employing the PV scaling.

The model's ability to simulate the regionally averaged vertical profiles sampled by the aircraft over the subtropical and subarctic Pacific is illustrated in Fig. 5e and f, respectively. In constructing these composite average vertical $\mathrm{O}_{3}$ profiles, the observed and the modeled data were averaged within each $500 \mathrm{~m}$ vertical bin and over all the flights in that region; the figure also shows the SD for the observations. These vertical profiles represent the mean conditions that occurred over the subtropical and subarctic Pacific during the study period. The model tracks the composite average gradients within the lower and upper troposphere in these regions and accurately simulates that there is higher $\mathrm{O}_{3}$ in the subarctic Pacific upper troposphere relative to the subtropical Pacific. Also apparent in these comparisons is the systematic and large underestimation of $\mathrm{O}_{3}$ throughout the troposphere in the simulation that did not account for any contributions due to STE processes. The much-closer agreement of the observed composite profile with that derived from the simulations with the PV scaling further suggests that on average $\sim 10 \mathrm{ppb}$ (or greater) of the $\mathrm{O}_{3}$ in the troposphere 
(a)

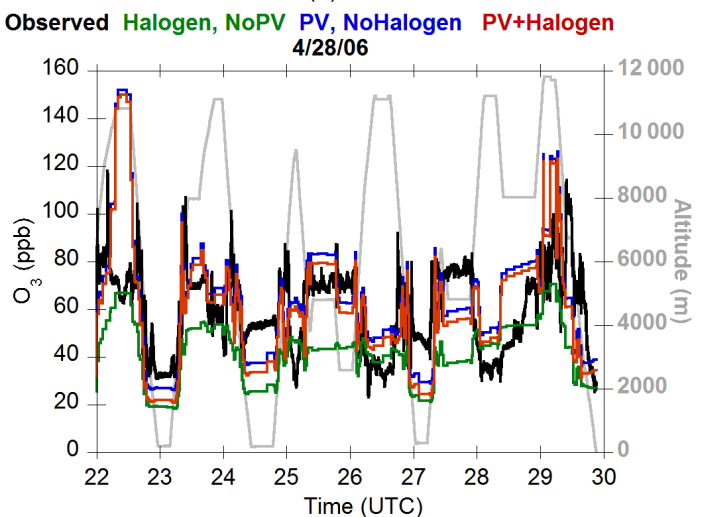

(c)

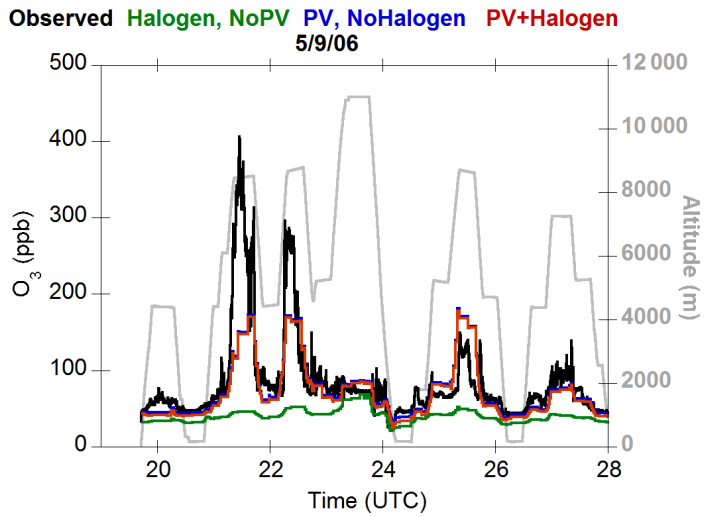

(e)

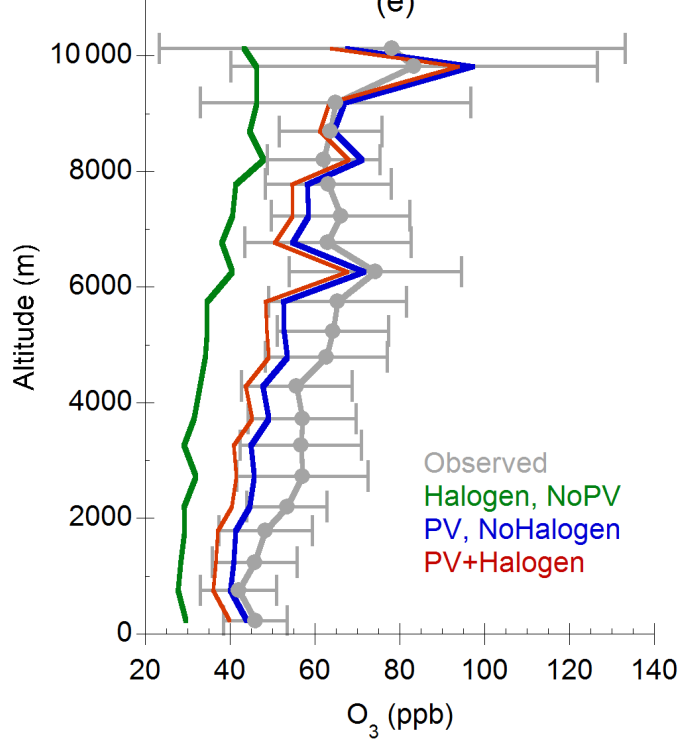

(b)

Observed Halogen, NoPV PV, NoHalogen PV+Halogen

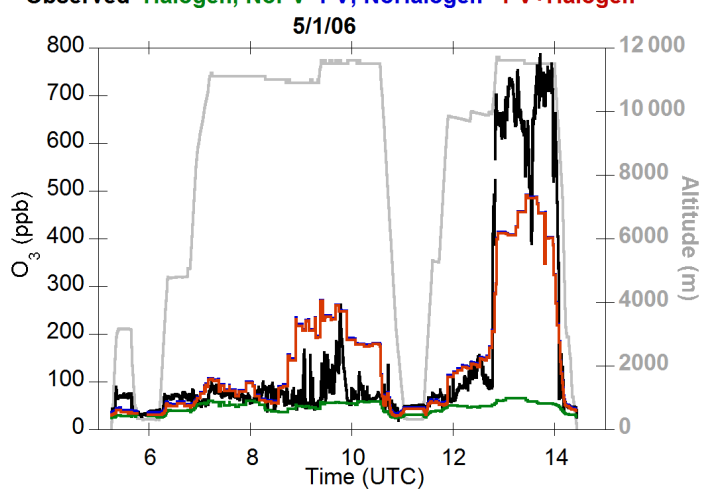

(d)

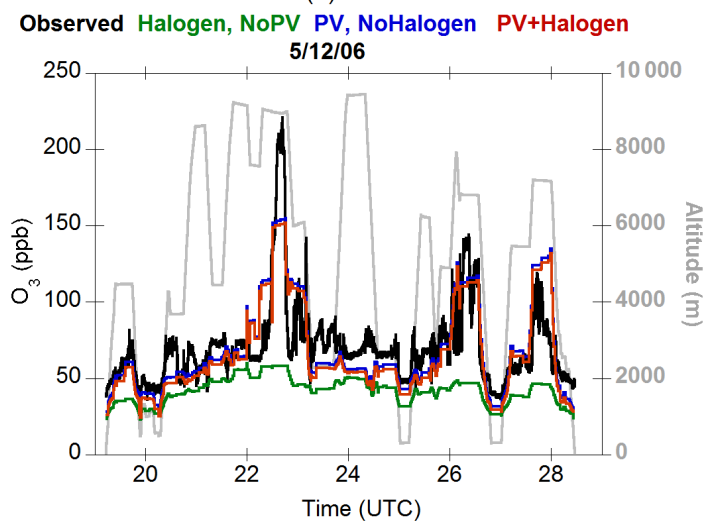

(f)

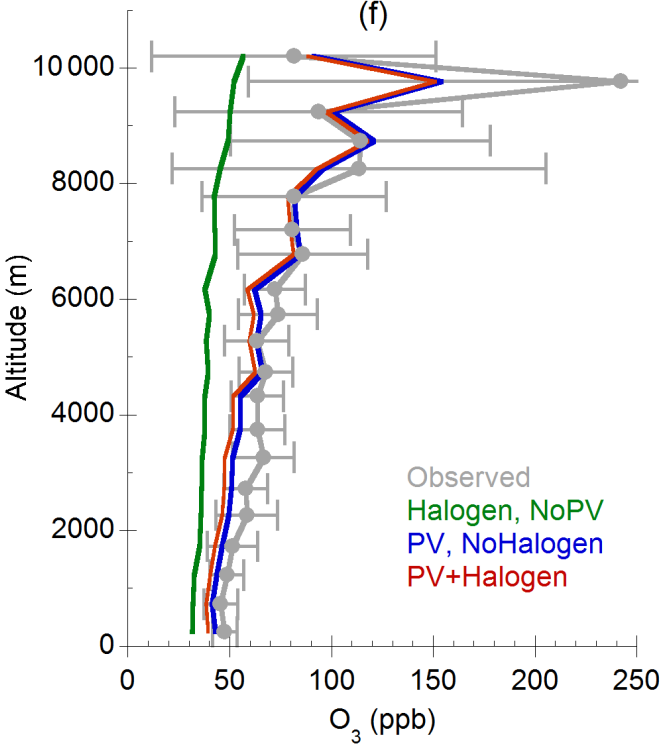

Figure 5. Comparison of simulated 3-D distributions of $\mathrm{O}_{3}$ mixing ratios with observations from the DC-8 aircraft during the INTEX-B field campaign: (a-d) comparison of observed $\mathrm{O}_{3}$ and simulated values from various model configurations along flight tracks on specific days; (e) comparison of model and observed campaign average $\mathrm{O}_{3}$ vertical profile for flights over the subtropical Pacific during 17 April1 May 2006; (f) comparison of model and observed campaign average $\mathrm{O}_{3}$ vertical profile for flights over the subarctic Pacific during 1-15 May 2006. Also shown in panels (e) and (f) is \pm 1 SD for the observed values. Also shown in panels (a-d) is the aircraft altitude along the flight path. 
over the Pacific during spring could be of stratospheric origin. Thus, $\mathrm{O}_{3}$ in air masses entering western North America is comprised of both anthropogenic contributions due to long-range transport of aged pollution from Asia and central America and a natural stratospheric component. The composite $\mathrm{O}_{3}$ vertical profile during this period derived from the hemispheric CMAQ is within the range of those predicted by other global atmospheric chemistry models illustrated in Singh et al. (2009).

Anthropogenic emissions from Asia are often lifted into the FT and transported across the Pacific to North America in 5-10 days (e.g., Jaffe et al., 1999). Enhancements to free-tropospheric $\mathrm{SO}_{4}^{2-}$ measurements over northwest North America have been attributed to Asian sources (e.g., Andreae et al., 1988; Barrie et al., 1994). Increasing $\mathrm{SO}_{2}$ emissions in Asia could potentially increase the amount of $\mathrm{SO}_{4}^{2-}$ imported to North America and impact local efforts to reduce regional haze and improve visibility in national parks. Consequently, developing tools that accurately characterize the long-range transport from source regions and the amount of aerosols (both natural and anthropogenic) in air masses imported into a region is needed. To assess the ability of the hemispheric CMAQ model to represent airborne $\mathrm{SO}_{4}^{2-}$ levels and gradients off the Pacific coast of North America, we compared model predictions of $\mathrm{SO}_{4}^{2-}$ (total of $\mathrm{SO}_{4}^{2-}$ in the Aitken and accumulation modes) distributions with measurements taken during the INTEX-B study. In addition to $\mathrm{SO}_{4}^{2-}$ measurements from bulk aerosol filters on the DC-8, measurements from the Particle Into Liquid Sampler (PILS) onboard the C-130 aircraft (11 flights) were also analyzed to evaluate the simulated $\mathrm{SO}_{4}^{2-}$ distributions within both the $\mathrm{BL}$ and FT over the eastern Pacific and western North America. Analysis of the evolution of the MODIS AOD retrievals during mid-April 2006 (van Donkelaar et al., 2008) documents the development and transport of an Asian plume to western north America, and transects of a C-130 flight on 21 April 2006 during 20:00-23:00 UTC sampled this plume in the FT off the coast of the western United States. Figure 6 illustrates the simulation of this episodic Asian plume transport event. The flight path (color-coded by UTC time) and sampling region are shown in Fig. 6a. Simulated transport features of the Asian $\mathrm{SO}_{4}^{2-}$ plume in the model layer at approximately $4 \mathrm{~km}$ altitude at 21:00 UTC on 21 April are illustrated in Fig. 6b while Fig. 6c presents space- and time-matched comparisons of the model results with measurements along the C-130 flight path. Both the MODIS retrievals (in van Donkelaar et al., 2008) and model simulations in Fig. $6 \mathrm{~b}$ show the export of $\mathrm{SO}_{4}^{2-}$ from East Asia and its eastward transport across the Pacific Ocean to the western coast of North America. As illustrated in Fig. 6c, $\mathrm{SO}_{4}^{2-}$ levels $>1 \mu \mathrm{g} \mathrm{m}^{-3}$ were often measured in the FT. Both the observations and model show these enhanced $\mathrm{SO}_{4}^{2-}$ levels at altitudes of 4-6 km, which in conjunction with the large-scale simulated $\mathrm{SO}_{4}^{2-}$ distributions in Fig. 6b, suggest that CMAQ captures the $\mathrm{SO}_{4}^{2-}$ enhancements in the FT associated with this episodic event. Some discrepancies in the space- and time-matched model and observed concentrations are also apparent in Fig. 6c, which likely result from the relatively coarse $(108 \mathrm{~km})$ horizontal grid resolution employed in the model calculations.

Comparisons of campaign-average composite vertical profiles for $\mathrm{SO}_{4}^{2-}$ for all the DC-8 and C-130 flights are shown in Fig. 7a and b, respectively. Relative to the observations, CMAQ tends to overestimate mean $\mathrm{SO}_{4}^{2-}$ levels, especially in the lower troposphere, as seen in the comparisons with the bulk filter measurements from the DC-8. It should be noted that the $\mathrm{C}-130$ PILS measurements represent $\mathrm{SO}_{4}^{2-}$ mass only for particle sizes $<1 \mu \mathrm{m}$, while the model values that are total mass in the Aitken and accumulation modes, nominally represent particle sizes $<2.5 \mu \mathrm{m}$. This discrepancy in particle size cutoffs between the measured and modeled $\mathrm{SO}_{4}^{2-}$ in part contributed to the systematic overestimation relative to the C-130 PILS measurements. In their comparisons with model results, van Donkelaar et al. (2008), for instance, used a factor of 1.4 to scale the PILS $\mathrm{SO}_{4}^{2-}$ during INTEX-B to account for particle size restrictions. Using a similar scaling here would result in a much closer comparison of the composite measured and modeled $\mathrm{SO}_{4}^{2-}$ profiles in Fig. 7.

\subsection{Episodic intercontinental transport of Saharan dust and impact on US air quality}

Some of the earliest recognition of long-range transport of air pollutants, dating back almost a century, was through observations of intercontinental transport of dust (Husar, 2004). North Africa is one of the largest sources of windblown dust, and the frequent transport of Saharan dust across the North Atlantic Ocean to the Caribbean has long been studied (e.g., Prospero and Carlson, 1972). Transatlantic transport of major Saharan dust outbreaks can episodically influence tropospheric particulate matter loading in the southeastern United States. The ability of the hemispheric CMAQ to simulate such long-range transport events is investigated through analysis of a Saharan dust transport event in late July-early August 2006. The simulated development and transatlantic transport of a Saharan dust plume during this period is illustrated in Fig. 8, which presents daily average enhancements in $\mathrm{PM}_{2.5}$ concentrations attributable to windblown dust. Large amounts of dust lofted into the atmosphere were transported west across the Atlantic, eventually impacting the Gulf of Mexico coast region of the United States. Surface-level $\mathrm{PM}_{2.5}$ measured in the US Gulf of Mexico states showed enhanced values as seen in the average concentrations across monitoring sites in Florida (Fig. 9b).

A demonstration of CMAQ's ability to simulate episodic long-range Saharan dust transport is shown using comparisons with surface-level $\mathrm{PM}_{2.5}$ measurements at the Air Quality System (AQS) monitors in the Gulf of Mexico states (Fig. 9). The average change in bias in modeled $\mathrm{PM}_{2.5}$ be- 
(a)

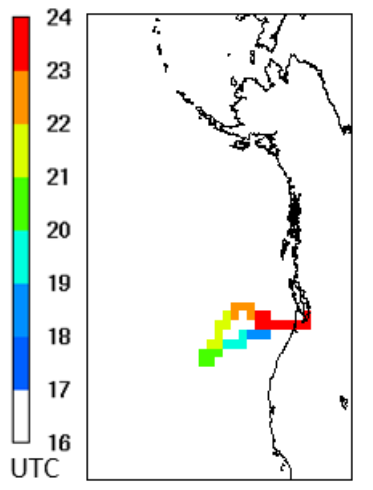

(b)

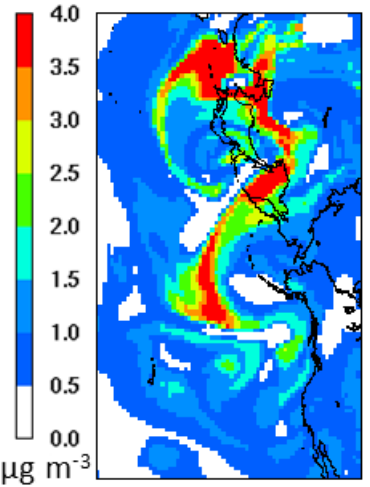

(c)

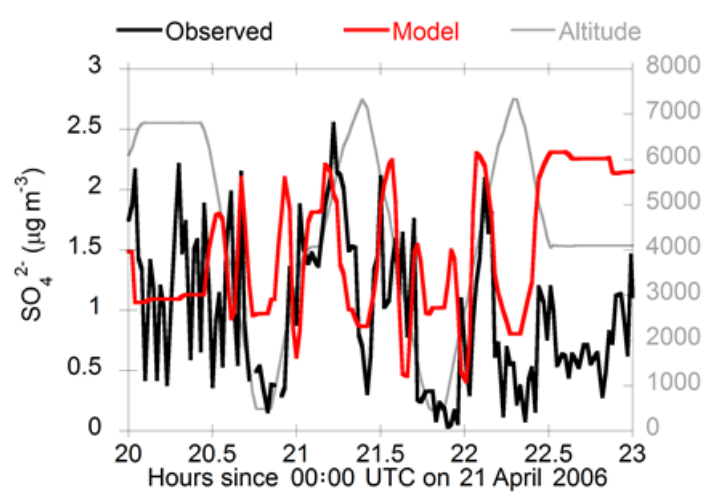

Figure 6. Simulation of the impact of transpacific transport on 3-D distributions of $\mathrm{SO}_{4}^{2-}$ aerosol on 21 April 2006. (a) Flight path of C-130 aircraft color-coded by hour (UTC). (b) Simulated $\mathrm{SO}_{4}^{2-}$ distribution at $4 \mathrm{~km}$ altitude on 21 April 2006 at 21:00 UTC. (c) Comparison of modeled and observed $\mathrm{SO}_{4}^{2-}$ aerosol concentrations along C-130 flight path.

(a)

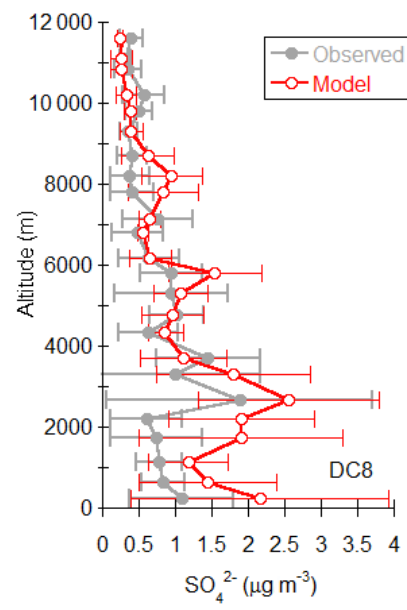

(b)

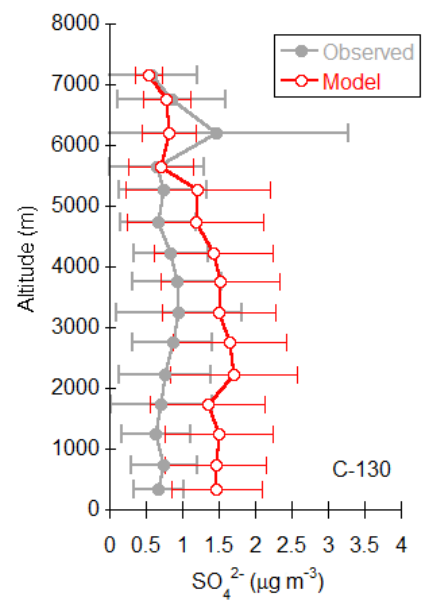

Figure 7. Comparison of modeled and observed campaign-average $\mathrm{SO}_{4}^{2-}$ vertical profiles: (a) against measurements from the DC-8 aircraft and (b) against measurements from the C-130 aircraft. Also shown is $\pm 1 \mathrm{SD}$ for both observed and modeled values.

tween simulations with and without dust emissions is shown in Fig. 9a, which indicates a reduction in bias in the simulation incorporating the impact of Saharan dust emissions and transport. Collectively, the analysis here and in Sect. 3.1 demonstrate that the hemispheric CMAQ modeling system can represent, with reasonable skill, the impacts of episodic transatlantic (Figs. 8 and 9) and transpacific (Figs. 6 and 7) transport events on air pollution over North America.

\subsection{Assessing the influence of stratosphere-troposphere exchange on surface $\mathrm{O}_{3}$}

The analysis of 3-D $\mathrm{O}_{3}$ distributions from model sensitivity simulations relative to aircraft measurements, discussed in Sect. 3.1, indicated the influence of STE processes on tropospheric $\mathrm{O}_{3}$ distributions over the Pacific during the INTEX-B study period. To further analyze impacts of STE on tropospheric and surface-level $\mathrm{O}_{3}$ over different seasons and regions, two simulations for the calendar year 2006 were conducted with the hemispheric CMAQ: with and without the dynamic PV-scaling approach discussed in Sect. 2.5. Figure 10 presents the simulated seasonal average influence of STE processes on daily maximum $8 \mathrm{~h}$ average (DM8) $\mathrm{O}_{3}$, estimated as the difference between the simulations with and without the dynamic PV-scaling parameterization. As can be seen, the amount of $\mathrm{O}_{3}$ at the surface that is of stratospheric origin varies substantially both spatially as well as seasonally. As expected, high-latitude regions typically show greater influence of STE at the surface. Also, the contributions to surface $\mathrm{O}_{3}$ from STE are much higher during spring and winter when height of the tropopause is lower (e.g., Elbern et al., 1998) and the stratospheric influence can penetrate far down to the lower troposphere (e.g., Wang et al., 2002).

Figure 11 presents an evaluation of the PV-scaling parameterization for representing the seasonal impacts of STE processes on surface $\mathrm{DM}_{3} \mathrm{O}_{3}$ relative to measurements from the CASTNET monitoring network in the United States. A third simulation of 2006 was conducted using a constant $\mathrm{O}_{3}-\mathrm{PV}$ scaling factor of $20 \mathrm{ppb} \mathrm{PVu}^{-1}$ rather than the dynamic scaling approach. The model-estimated stratospheric contribution to surface $\mathrm{DM}_{3} \mathrm{O}_{3}$ at the CASTNET locations can be estimated as the difference between the $\mathrm{DM} 8 \mathrm{O}_{3}$ from the simulations with and without the dynamic PV scaling. The bias 


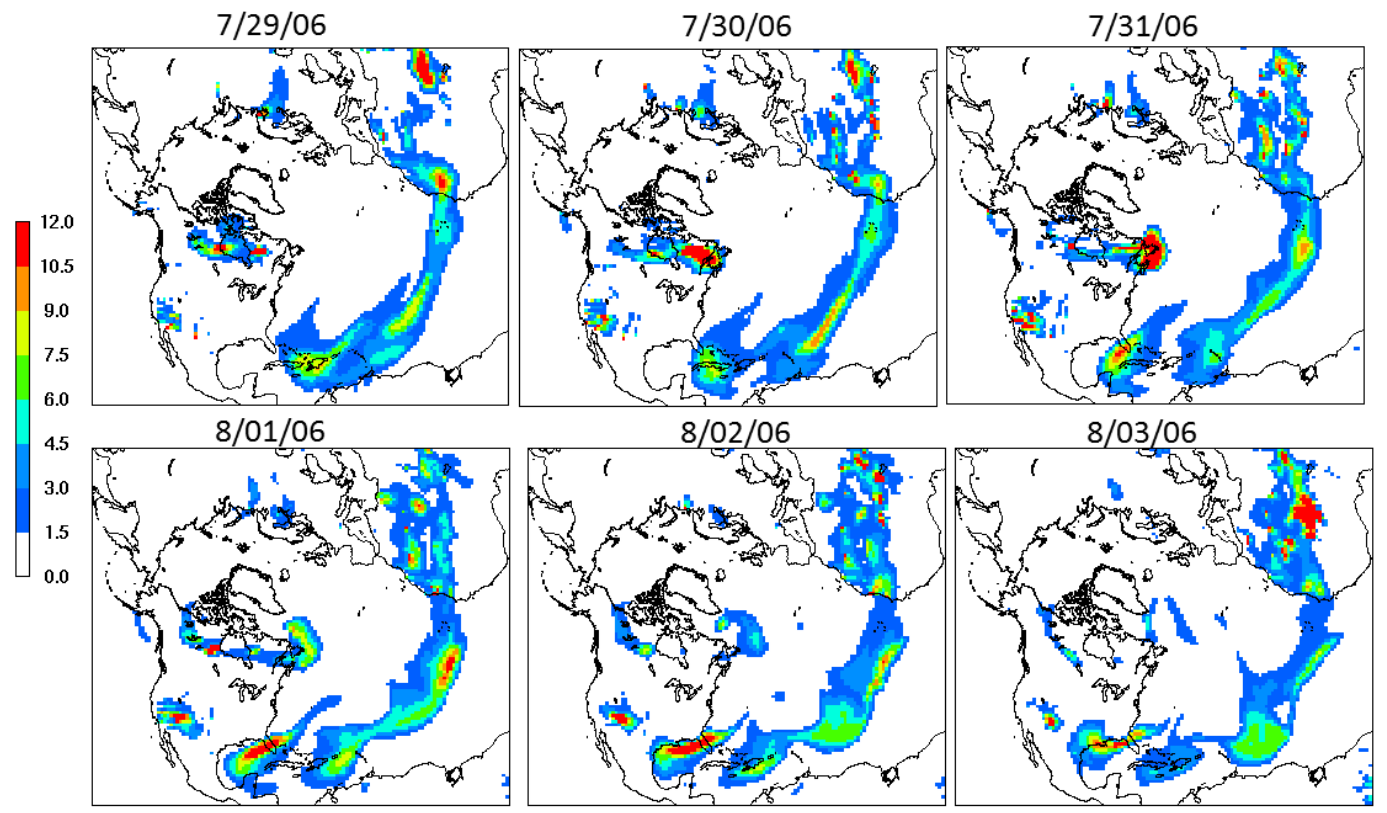

Figure 8. Transatlantic transport of a Saharan dust plume, 29 July-3 August 2006, as simulated by hemispheric CMAQ. Shown in the panels is the difference in daily-average $\mathrm{PM}_{2.5}$ concentrations $\left(\mu \mathrm{g} \mathrm{m}^{-3}\right)$ between CMAQ simulations with and without considering dust emissions.

(a)

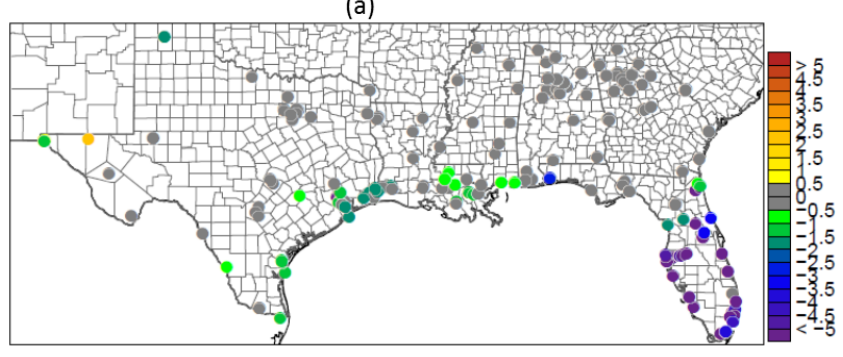

(b)

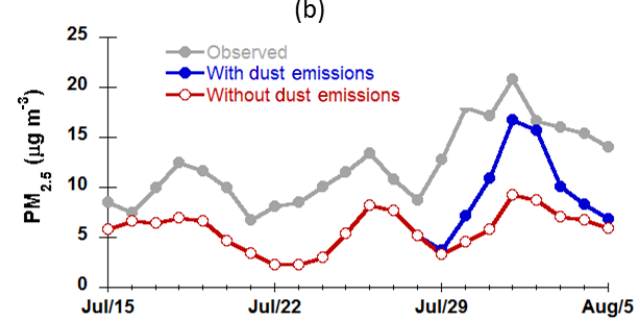

Figure 9. The impact of simulated transatlantic transport of Saharan dust on daily-average surface $\mathrm{PM}_{2.5}$ in the Gulf of Mexico region. (a) Average change in bias in daily average surface $\mathrm{PM}_{2.5}\left(\mu \mathrm{g} \mathrm{m}^{-3}\right)$ at AQS monitor locations between CMAQ simulations with and without considering dust emissions, 29 July-2 August 2006. Negative changes in bias denote improvement in model performance by including Saharan dust emissions and representing their transatlantic transport. (b) Comparison of modeled and observed dailyaverage surface $\mathrm{PM}_{2.5}$ averaged over all AQS monitor locations in Florida. in the $\mathrm{DM}_{3} \mathrm{O}_{3}$ predictions was computed at each location for the simulations with constant-PV and dynamic-PV parameterizations. A reduction in bias between these two simulations is a relative measure of the improvements in surface $\mathrm{O}_{3}$ predictions from using the dynamic-PV parameterization. Figure 11 correlates the seasonal average of this bias change with the estimated stratospheric contribution. The calculated seasonal means at each location were restricted to days with observed $\mathrm{DM} \mathrm{O}_{3}>40 \mathrm{ppb}$. This helps screen out days when low $\mathrm{O}_{3}$ may not be captured due to model grid resolution or other process limitations and limited the analysis to periods in which STE influences were likely greater. A strong linear relationship is noted in Fig. 11 between the bias change and estimated stratospheric contribution. Across all seasons and at most locations, the dynamic-PV parameterization reduced the bias in predicted surface $\mathrm{DM} 8 \mathrm{O}_{3}$ relative to the constant-PV scaling. More importantly, when the estimated stratospheric contribution to surface $\mathrm{O}_{3}$ is high, greater reductions in model $\mathrm{DM} 8 \mathrm{O}_{3}$ error are realized through the use of the dynamic-PV scaling parameterization, demonstrating the ability of the PV-based parameterization in representing the effects of STE on surface $\mathrm{O}_{3}$ levels and its seasonal and spatial variability. Additionally, the improvements in model predictions (i.e., reduction in model bias) of $\mathrm{DM} \mathrm{O}_{3}$ are also greater during spring and winter when the stratospheric contributions are higher (Fig. 10). These evaluation results help build further confidence in the use of the dynamic-PV scaling parameterization in the hemispheric CMAQ model and for representing the impact of STE processes on surface $\mathrm{O}_{3}$ levels. 
(a) Spring

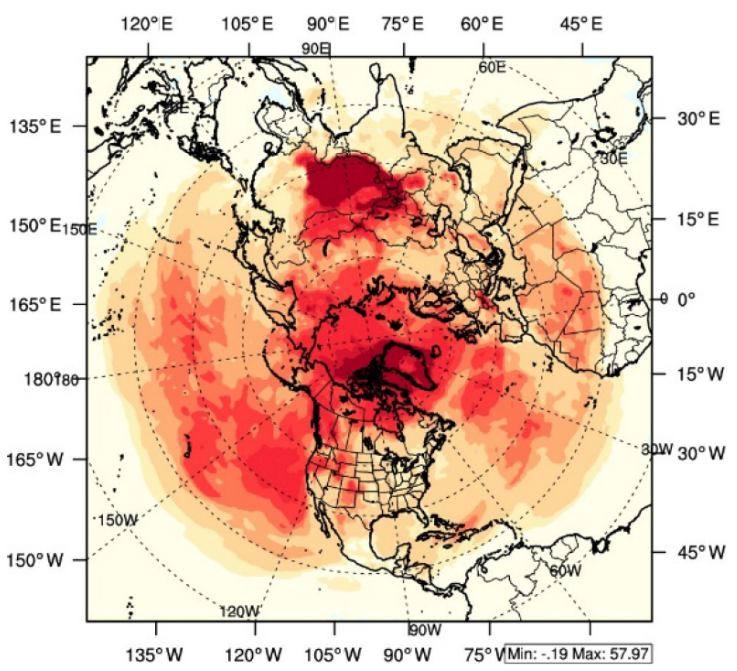

(c) Fall

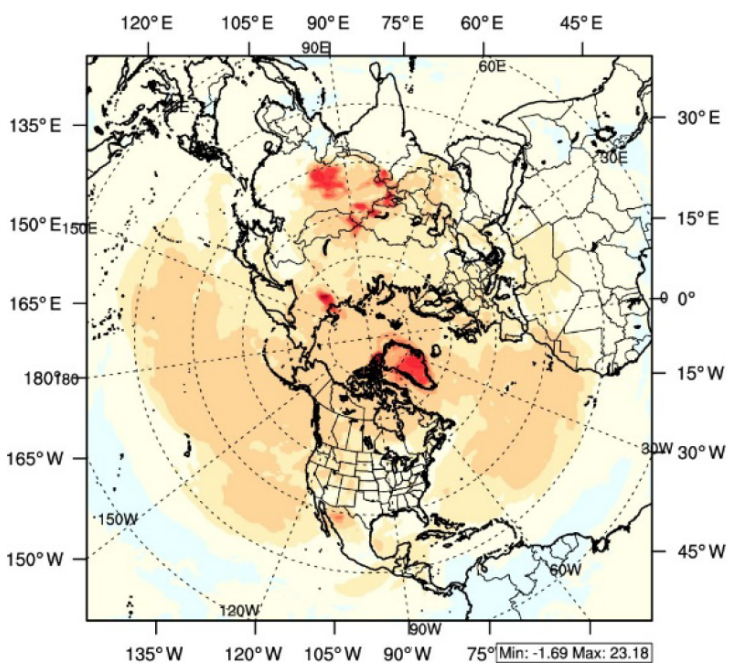

(b) Summer
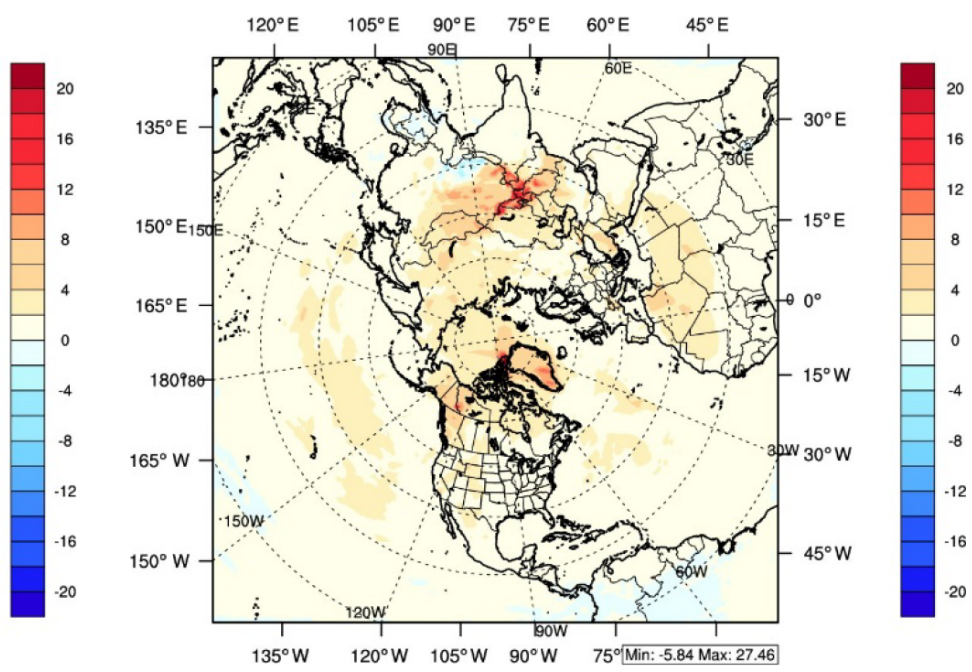

(d) Winter

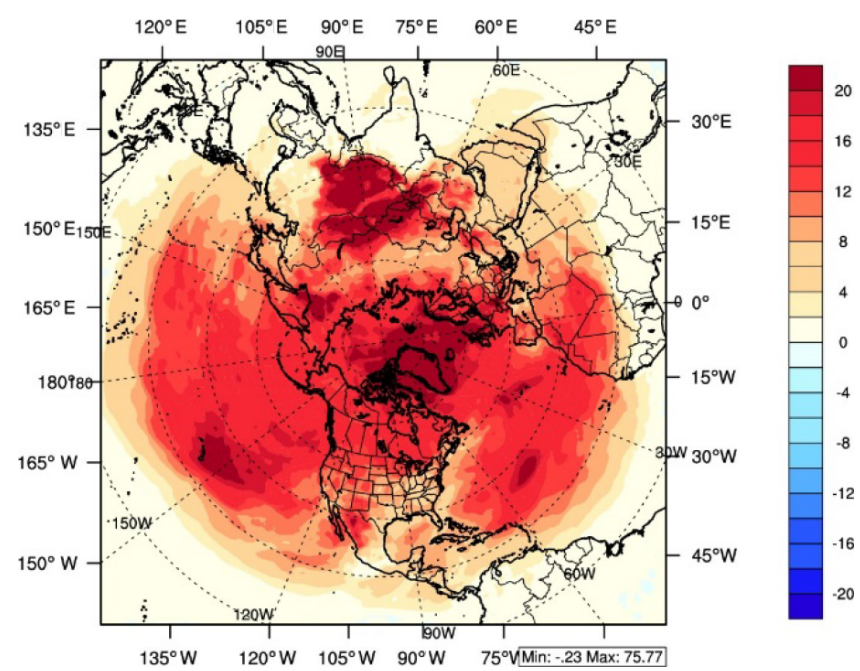

Figure 10. Impact of dynamic-PV scaling on surface-level seasonal mean maximum daily $8 \mathrm{~h}$ average $\mathrm{O}_{3}\left(\mathrm{MD}_{3} \mathrm{O}_{3}\right)$ mixing ratios (ppb) estimated as the difference between the simulation with and without the dynamic-PV formulation.

\subsection{Comparison of $\mathrm{O}_{3}$ predictions using the $\mathrm{RACM}$ and CB05 mechanisms}

As mentioned in Sect. 2.4.3, the RACM2 is also available as an alternate and more detailed representation of gas-phase atmospheric chemistry for hemispheric-scale CMAQ applications. A detailed comparison of the CB05TU and RACM2 predictions for regional scale applications over the continental United States was described in Sarwar et al. (2013). A brief summary of comparisons of tropospheric $\mathrm{O}_{3}$ predictions using the two mechanisms in hemispheric CMAQ is presented in Fig. 12. The simulations were conducted for May-August 2006 and were initialized using chemical fields from an existing longer-term simulation. Differences in predictions of surface-level monthly mean $\mathrm{O}_{3}$ mixing ratios across the Northern Hemisphere using the RACM2 and CB05TU mechanisms are illustrated in Fig. 12a for August 2006. Note that the simulations denoted CB05TU and RACM2 did not include representation of halogen chemistry. In the simulation using the RACM2, higher $\mathrm{O}_{3}$ is noted in polluted regions (regions with higher $\mathrm{NO}_{x}$ in Fig. 13e), but lower values are seen in the remote areas. These differences arise primarily due to higher rates of $\mathrm{NO}_{x}$ recycling from organic nitrates and more active organic chemistry in RACM2.

To further assess the impacts of using different chemical mechanisms on $3-\mathrm{D} \mathrm{O}_{3}$ predictions, modeled $\mathrm{O}_{3}$ dis- 


\section{Spring Summer Fall Winter}

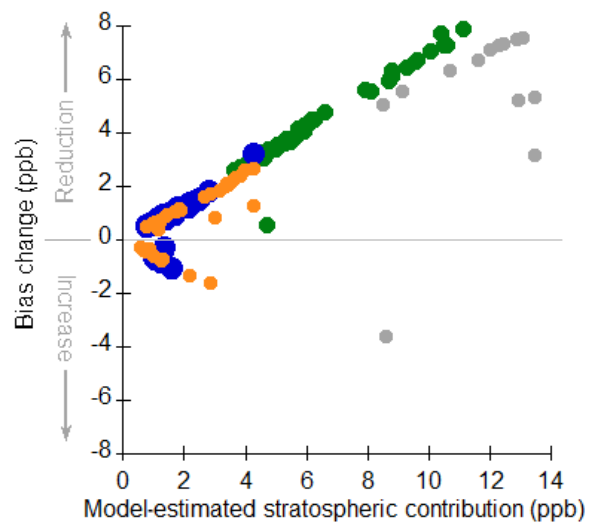

Figure 11. Impact of dynamic-PV scaling parameterization on model performance for surface-level seasonal mean maximum daily $8 \mathrm{~h}$ average $\mathrm{O}_{3}\left(\mathrm{MD}_{3} \mathrm{O}_{3}\right)$ at CASTNET sites in the United States. The model-estimated stratospheric contribution is estimated as the difference between the simulation with the dynamic-PV scaling and one without. The bias change is estimated as the difference between the absolute bias in the simulation with a constant-PV (20 PV) scaling and the absolute bias in the dynamic-PV scaling simulations. Positive changes in bias represent reduction in bias due to dynamic $\mathrm{PV}$, while negative changes represent an increase in bias in simulated surface $\mathrm{MD} \mathrm{O}_{3}$. Seasonal means are computed based on model-observed pairs when the observed $\mathrm{MD}_{3}>40 \mathrm{ppb}$.

tributions were compared with ozonesonde measurements at Sable Island, Nova Scotia; Trinidad Head, California; and Hilo, Hawaii. Comparisons of monthly mean $\mathrm{O}_{3}$ vertical profiles simulated using different chemical mechanisms with corresponding observed profiles are shown in Fig. 12bd. Also shown are predictions with a model configuration in which the RACM2 mechanism was augmented with the halogen chemistry described in Sect. 2.4.2. At Sable Island, which often receives outflow from the US northeast corridor, RACM2 overpredicts $\mathrm{O}_{3}$ at lower altitudes. The higher $\mathrm{O}_{3}$ relative to CB05TU in the North American outflow is likely due to the faster $\mathrm{NO}_{x}$ recycling in RACM2 as discussed earlier. At Trinidad Head, both RACM2 and CB05TU overestimate $\mathrm{O}_{3}$ near the surface, though RACM2 is closer to the observations at altitudes of $1000-3000 \mathrm{~m}$. In contrast, at Hilo CB05TU overestimates $\mathrm{O}_{3}$, and RACM2 is much closer to the observed profile. In general, the addition of halogen chemistry in RACM2 helps reduce the overestimation at lower altitudes. At altitudes $>1 \mathrm{~km}$, the RACM2 $\mathrm{O}_{3}$ predictions are generally in closer agreement with the observations at all three sites. These mixed performance results indicate that neither mechanism is necessarily better suited over the other for hemispheric-scale calculations. Nevertheless, analysis with both the CB05TU and RACM2 demonstrate the importance of $\mathrm{NO}_{x}$ recycling from isoprene nitrates and halogen chemistry on simulated $\mathrm{O}_{3}$ distributions. Addi- tional analyses of $\mathrm{NO}_{y}$ partitioning and $\mathrm{HO}_{x}$ predictions is needed to gain further insights into the reasons for the differences between the behaviors of the two mechanisms.

\subsection{Simulating long-term trends in tropospheric composition}

Over the past 2 decades significant and contrasting changes have occurred in anthropogenic air pollutant emissions across the globe. Emission control measures implemented in North America and western Europe have led to improvements in air quality in these regions. In contrast, due to increasing energy demand associated with rapidly growing economies and population, many regions in Asia and Africa are experiencing a dramatic increase in emissions of pollutants. These spatially heterogeneous emission trends across the globe have not only resulted in contrasting changes in human exposure levels to air pollution (e.g., Wang et al., 2017) but also likely impact long-range transport patterns and influence background air pollution levels in receptor regions. Accurate characterization of these changes in the chemical state of the troposphere (and potential influences on atmospheric dynamics) is needed to guide future control measures aimed at protecting human and environmental health. To assess these contrasting changes in air pollution levels, the hemispheric CMAQ was used to simulate trends in air quality across the Northern Hemisphere over a 21-year period (1990-2010). Year-specific emission inputs were derived from the Emission Database for Global Atmospheric Research (EDGAR, version 4.2) database (European Commission, 2011) as discussed earlier in Sect. 2.3.1 and detailed in Xing et al. (2015a).

Satellite-based tropospheric $\mathrm{NO}_{2}$ measurements now provide valuable observable information on the changing emission patterns and air quality across the globe (e.g., Richter et al., 2005; van der A et al., 2008). To determine if the model can capture the impact of these changing emissions on tropospheric composition, trends in model tropospheric vertical column densities (VCDs) of $\mathrm{NO}_{2}$ were compared with those derived from radiances measured by the satellite instruments GOME (Global Ozone Monitoring Experiment) and SCIAMACHY (Scanning Imaging Absorption spectrometer for Atmospheric CartograpHY). Note that the model $\mathrm{NO}_{2}$ column is estimated by integrating the predicted $\mathrm{NO}_{2}$ fields through the model column from the surface to $\sim 50 \mathrm{hPa}$ and did not utilize an averaging kernel. GOME $\mathrm{NO}_{2}$ observations are available from 1995 to 2003, while SCIAMACHY $\mathrm{NO}_{2}$ retrievals have been available since 2002. Figure 13a, $\mathrm{b}, \mathrm{d}$, and e compare annual mean tropospheric vertical column $\mathrm{NO}_{2}$ for the calendar years 2003 and 2010 derived from SCIAMACHY retrievals and hemispheric CMAQ. Spatial distributions of the estimated 2003-2010 trends in $\mathrm{NO}_{2} \mathrm{VCD}$ from SCIAMACHY and the model are presented in Fig. 13c and $\mathrm{f}$, respectively. 
(a)

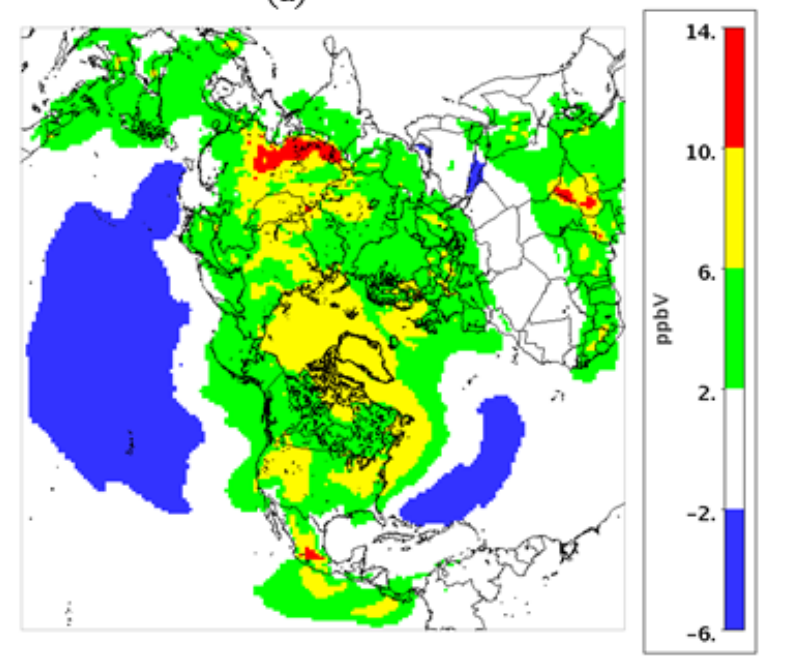

(c)

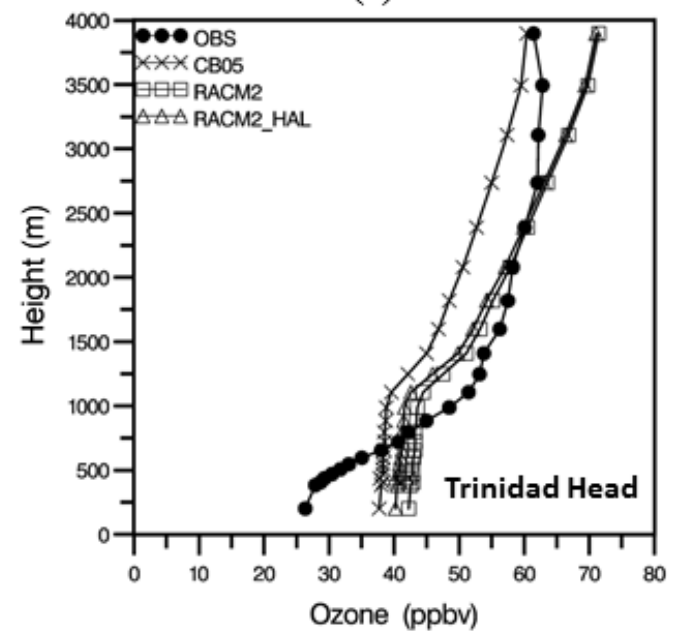

(b)

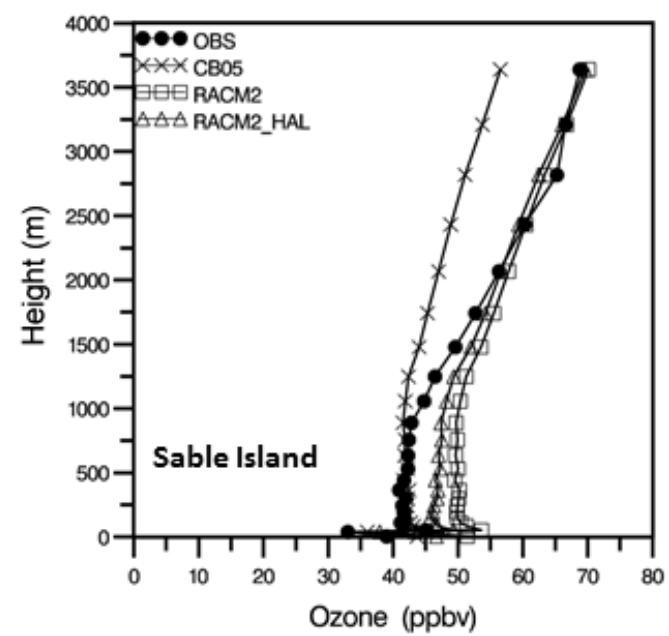

(d)

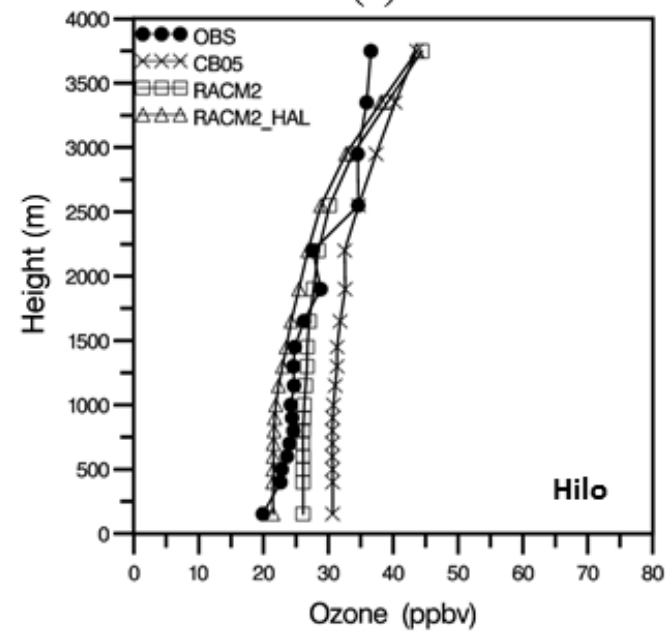

Figure 12. Differences in simulated $\mathrm{O}_{3}$ distributions using the RACM2 and CB05TU gas-phase chemical mechanisms in the hemispheric CMAQ model. (a) Mean difference (RACM2 minus CB05TU) in monthly mean surface-level $\mathrm{O}_{3}$ (ppb) for August 2006. Comparisons of mean (for August 2006) $\mathrm{O}_{3}$ mixing ratio vertical profiles simulated with the CB05TU and RACM2 mechanisms with ozonesonde measurements at (b) Sable Island, Nova Scotia; (c) Trinidad Head, California; and (d) Hilo, Hawaii. RACM2_HAL is from a simulation in which the RACM2 mechanism was augmented with halogen chemistry (described in Sect. 2.4.2).

Figure 13 shows that the spatial distributions of $\mathrm{NO}_{2} \mathrm{VCD}$ across the Northern Hemisphere are generally well correlated between CMAQ and SCIAMACHY, with higher $\mathrm{NO}_{2}$ in the industrial and urban areas of North America, Europe, and Asia. Some discrepancies are noted in central Africa where CMAQ simulates higher tropospheric $\mathrm{NO}_{2}$ in the Central African Republic and its northern border with Chad. Trends in $\mathrm{NO}_{x}$ emissions derived from the EDGAR inventory show a similar increasing trend in this region (see Fig. $2 b$ in Xing et al., 2015a) and indicate that this discrepancy is associated with the underlying emission data set used in these simulations. In contrast, SCIAMACHY distributions in the region show a signal associated with biomass burning in the savanna region of Africa both in 2003 and 2010 - the spatial extent of which is not captured by the model. Comparison of 2003-2010 trends in tropospheric $\mathrm{NO}_{2}$ between the CMAQ simulations and SCIAMACHY also indicate that the model captures increases in eastern China, and many cities in India and the Middle East as well as the decreases across the eastern United States, southern California, and western Europe. Figure 14 presents comparisons of time series of regionalaverage monthly mean variations in tropospheric $\mathrm{NO}_{2}$ simulated by the model with corresponding values based on the GOME and SCIAMACHY retrievals for three regions: eastern China, United States, and Europe (see Fig. 3 of Xing et al., 2015a for sub-domain extents). The domain-mean sea- 
(a) SCIAMACHY; 2003

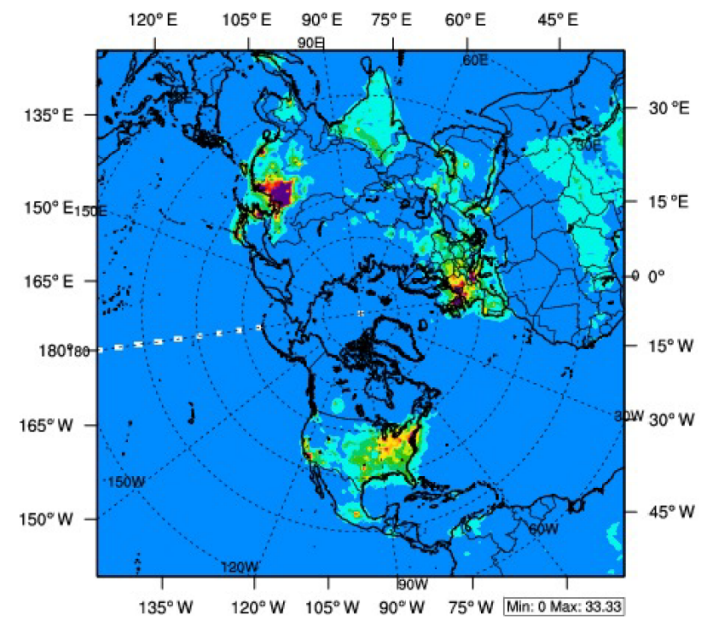

(b) SCIAMACHY; 2010

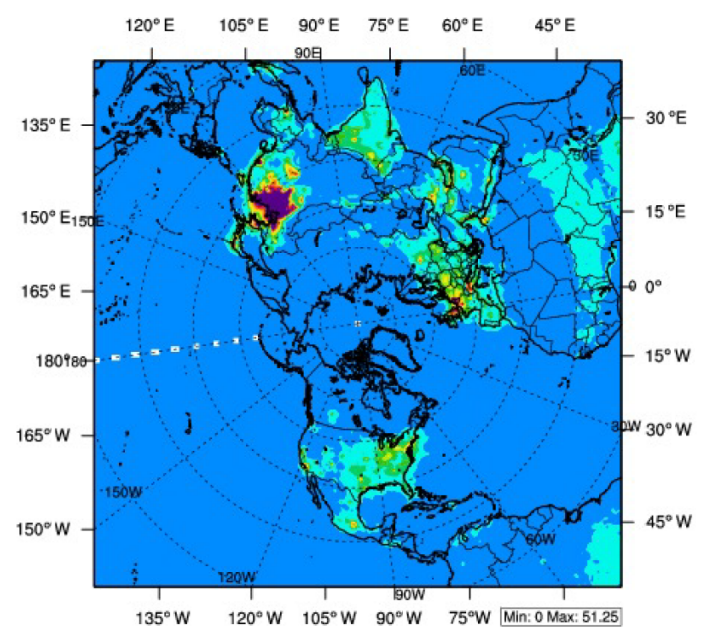

(c) SCIAMACHY 2003-2010 trend

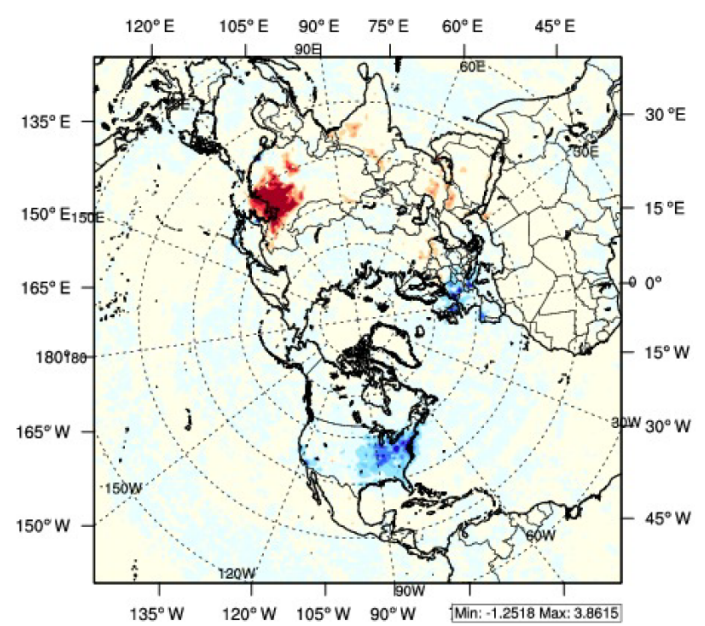

(d) CMAQ; 2003
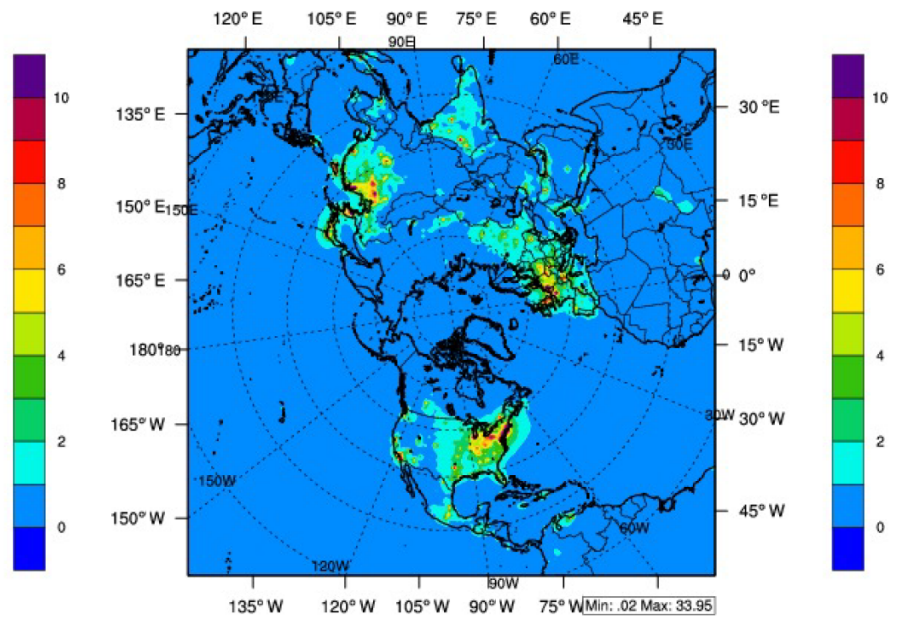

(e) CMAQ; 2010

$120^{\circ} \mathrm{E} \quad 105^{\circ} \mathrm{E} \quad 90^{\circ} \mathrm{E} \quad 75^{\circ} \mathrm{E} \quad 60^{\circ} \mathrm{E} \quad 45^{\circ} \mathrm{E}$

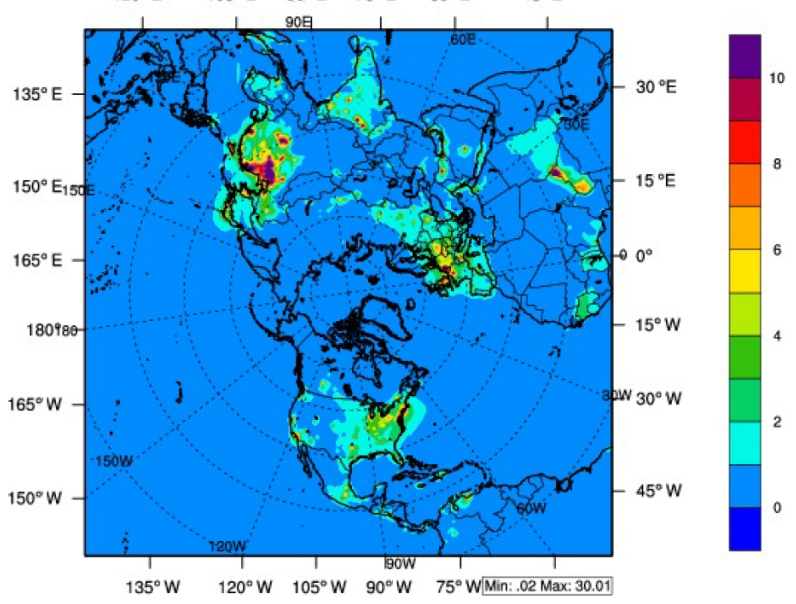

(f) CMAQ 2003-2010 trend

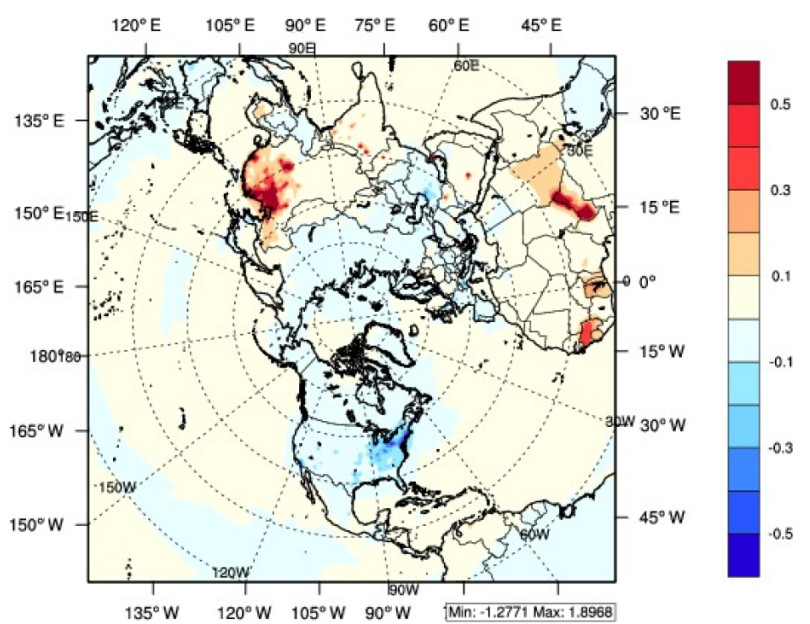

Figure 13. Comparison of observed (left) and model (right) changes in $\mathrm{NO}_{2}$ vertical column density (VCD) across the Northern Hemisphere. Panel (a) shows 2003 SCIAMACHY NO 2 VCD; (b) 2010 SCIAMACHY NO 2 VCD; (c) SCIAMACHY NO 2 VCD trend; (d) 2003 CMAQ

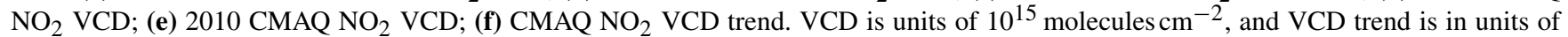

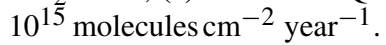


sonal variability in tropospheric $\mathrm{NO}_{2}$ (as represented by the GOME and SCIAMACHY retrievals) is captured reasonably well by the model with a cool season maximum and warm season minimum. The model accurately simulates the amplitude of this variability for the United States as well as its interannual variability. For East Asia the model underestimates the peak values. In contrast for Europe, relative to both GOME and SCIAMACHY, the model consistently overestimates the summertime minimum values. Note that these simulations did not account for aerosol radiative feedback effects, which, due to scattering and absorption of incoming solar radiation, reduce the amount of radiation impinging the Earth's surface. The resulting stabilization can reduce BL ventilation and increase surface-level concentrations. As shown in Xing et al. $(2015 b, c)$ these effects are especially important in polluted environments such as East Asia. Consequently, some of the underestimation in tropospheric $\mathrm{NO}_{2}$ over East Asia during the cooler months (when particulate matter pollution is the highest) could also arise from ignoring the aerosol direct radiative effects on simulated concentrations.

In addition to $\mathrm{NO}_{x}$, anthropogenic emissions of $\mathrm{SO}_{2}$ and VOCs have also been reduced significantly in the United States. To assess the impact of these precursor emission changes on trends in concentrations of secondarily produced species, we compared model-simulated trends in ambient $\mathrm{O}_{3}$ and aerosol $\mathrm{SO}_{4}^{2-}$ with those inferred from measurements at the CASTNET monitors. Figure 15 presents comparisons of model and observed trends in average summer, daily maximum, $8 \mathrm{~h}$ average $\mathrm{O}_{3}$ and average summer weekly-average $\mathrm{SO}_{4}^{2-}$ at each CASTNET monitor site. Trends are estimated as the slope of the linear regression of these concentration metrics for the 21-year period. Also shown in Fig. 15 are results from an additional 21-year simulation with CMAQ that used a $36 \mathrm{~km}$ resolution regional domain focused on the contiguous United States (see Fig. 2). This regional simulation used an updated long-term emission inventory for the United States (Xing et al., 2013) and was driven by space- and timevarying lateral boundary conditions from the hemispheric CMAQ simulations for 1990-2010 (Gan et al., 2015a). Figure 15 shows that both the hemispheric-scale and the nested regional model capture the decreasing trends in both $\mathrm{DM} 8 \mathrm{O}_{3}$ and $\mathrm{SO}_{4}^{2-}$ as well as the spatial variability in the magnitude of the trends across the CASTNET sites, though the hemispheric model tends to underestimate the magnitude of the trends by $25-47 \%$. However, the finer resolution of the nested simulation in conjunction with the updated emission inventory better captures the observed trends in surface-level $\mathrm{DM}_{8} \mathrm{O}_{3}$ and $\mathrm{SO}_{4}^{2-}$ as indicated by slopes closer to unity. This suggests the need to further explore finer-resolution model calculations with the hemispheric CMAQ. As computing resources increase in the future it may be possible to conduct hemispheric-scale simulations utilizing grid spacing finer than the $108 \mathrm{~km}$ utilized here. (a) East China

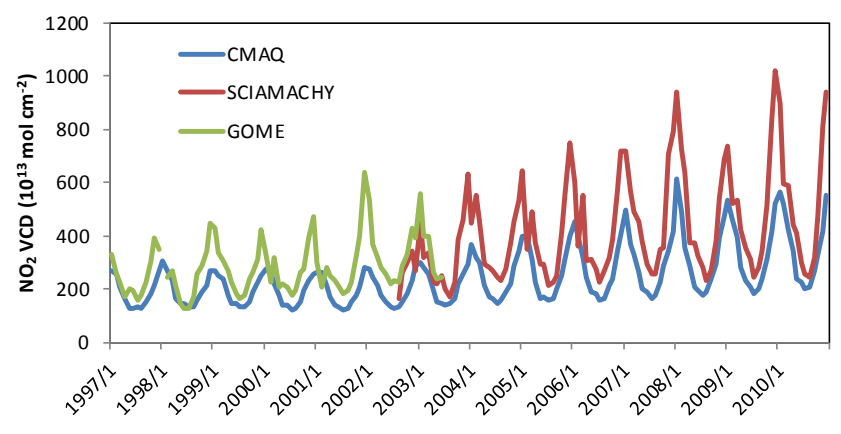

(b) United States

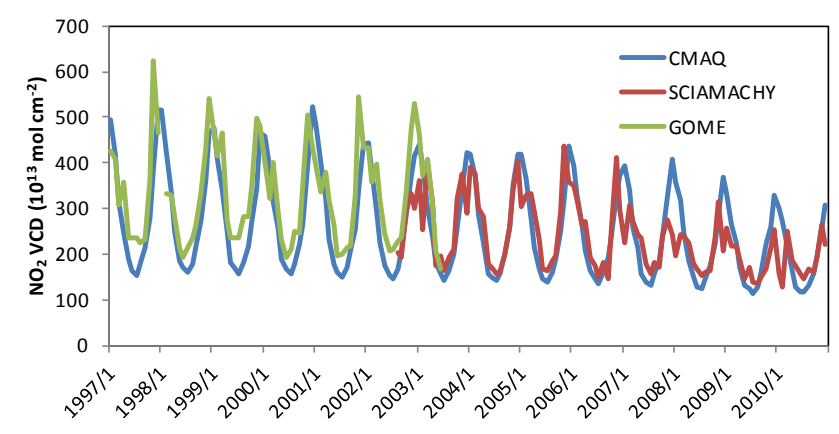

(c) Europe

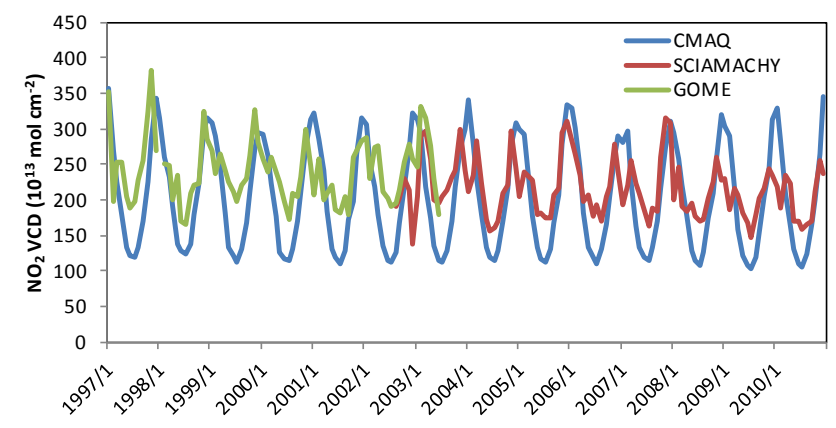

Figure 14. Comparison of changes in regional- and monthlyaverage modeled $\mathrm{NO}_{2}$ vertical column density with satellite retrievals from SCIAMACHY and GOME for (a) East Asia, (b) the United States, and (c) Europe.

\subsection{Assessment of representation of aerosol direct radiative effects}

Both aerosol scattering and absorption reduce the SWR impinging on the Earth's surface. The variability in surface solar radiation plays a prominent role in the Earth's climate system as it contributes to the modulation of the surface temperature, intensity of the hydrological cycle, and potentially the net ecosystem productivity (Wild, 2009). Observed trends in solar radiation reaching the Earth's surface are very likely associated with changes in aerosol and aerosol-precursor emissions governed by economic development and air pol- 

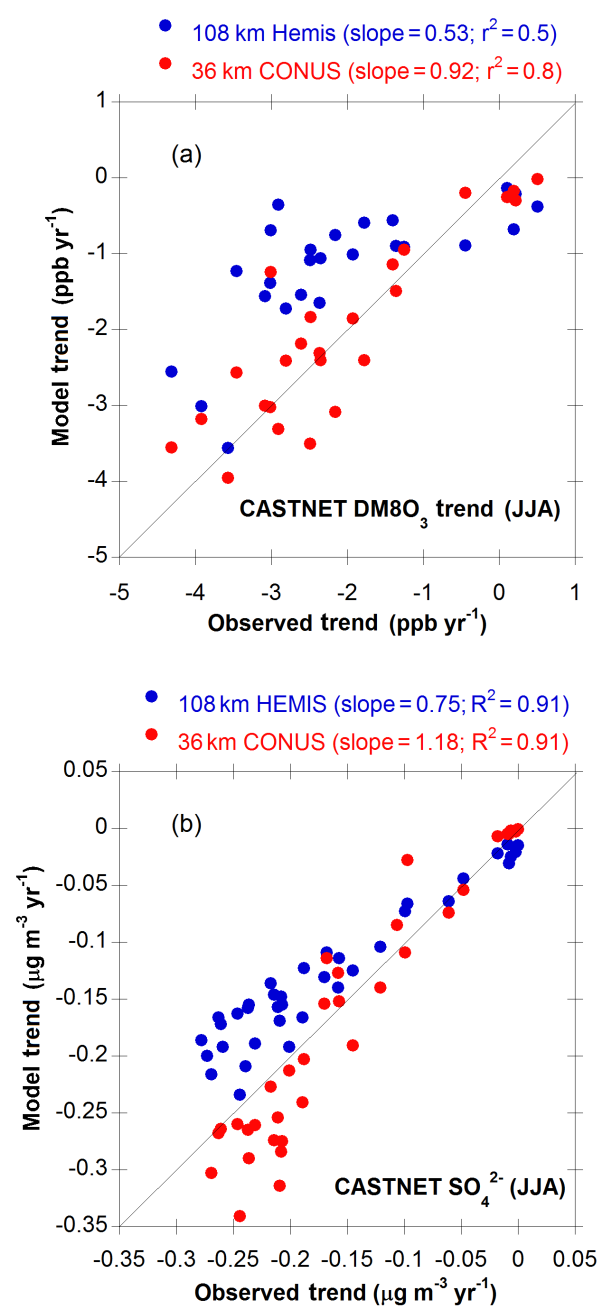

Figure 15. Comparison model and observed summertime (JJA) 1990-2010 trends at CASTNET monitoring sites in the United States for (a) JJA average daily maximum $8 \mathrm{~h}$ average $\mathrm{O}_{3}$ and (b) JJA average $\mathrm{SO}_{4}^{2-}$. Model results from the $108 \mathrm{~km}$ resolution hemispheric CMAQ simulation are shown in blue, while results from a $36 \mathrm{~km}$ resolution nested model calculation over the contiguous United States are shown in red.

lution regulations, which have modulated the trends in regional and global tropospheric aerosol burden over the past 2 decades (see Wild, 2009; Streets et al., 2009). Surface solar radiation "dimming" and "brightening" effects respectively dampen and enhance the warming trends induced by greenhouse gasses; thus, it is essential to accurately characterize these trends and quantify the role of regional variability in tropospheric aerosol burdens on these trends.

Simulations over the Northern Hemisphere can also be conducted using a two-way coupled WRF-CMAQ configuration (Wong et al., 2012), in which CMAQ-simulated aerosol composition and size distribution are used to estimate their optical properties, which are then fed back to the WRF radiation module to influence the radiation sim- ulated by WRF. Thus, the effects of aerosol scattering and absorption of incoming radiation can further impact the simulated atmospheric dynamics (BL heights, temperature, simulated resolved, and sub-grid-scale clouds), which then impact emission rates, transport and dispersion, deposition, and temperature- and actinic-flux-dependent chemical rate constants. The aerosol optical properties in the two-way coupled WRF-CMAQ are calculated using the BHCOAT coatedsphere module approach (Bohren and Huffman, 1983), i.e., particles in the Aitken and accumulation model are assumed to have a core composed of elemental carbon with a shell coating of other species. The aerosol optic calculations in WRF-CMAQ have been evaluated against field measurements as detailed in Gan et al. (2015b).

In addition to the long-term (1990-2010) simulations discussed in Sect. 3.5, additional feedback simulations were conducted over the Northern Hemisphere with the two-way coupled WRF-CMAQ configuration for the summer months (June, July, and August) of this 21-year period. Comparison of these two sets of simulations (with and without aerosol feedbacks) provides an indication of the impact of the aerosol direct radiative effects and an assessment of its trends associated with the changing tropospheric aerosol burden over the multi-decadal period. Figure 16 examines the modeled and observed relationships between changes in AOD (representing changes in the tropospheric aerosol burden) and changes in clear-sky surface SWR using regional monthly averages for eastern China, Europe, and the eastern United States. Figure 16 examines 2000-2010, when satellite-based data were available. Monthly regional averages of SWR and AOD values were calculated for each of the summer months (June, July, and August). To minimize the influence of month-tomonth variability, monthly averaged SWR and AOD were deseasonalized by subtracting the average of 11 year data for the corresponding month. Additionally, we used $24 \mathrm{~h}$ averaged SWR but AOD at noon (local time) for model values to be consistent with the observation-derived data from satellite retrievals (Xing et al., 2015b). The relationship between these deseasonalized values (or anomaly) of SWR and AOD for each summer month in the 2001-2010 period is examined in Fig. 16 for model simulations both with and without direct aerosol feedback effects. Also shown in Fig. 16 is the corresponding observed relationship between the similarly estimated AOD anomaly and SWR anomaly derived from retrievals from the MODIS and the Clouds and the Earth's Radiant Energy System (CERES; Wielicki et al., 1998) instruments, respectively. Note that the CERES mission estimates clear-sky surface SWR through radiative transfer calculations using satellite-retrieved surface, cloud, and aerosol properties as input (Kato et al., 2013), which have also been shown to agree with surface observations (Wild et al., 2013).

All three regions show a strong relationship between observed changes in AOD and clear-sky surface SWR, with reductions in SWR associated with increases in AOD and increases in SWR with reductions in AOD. This observational 

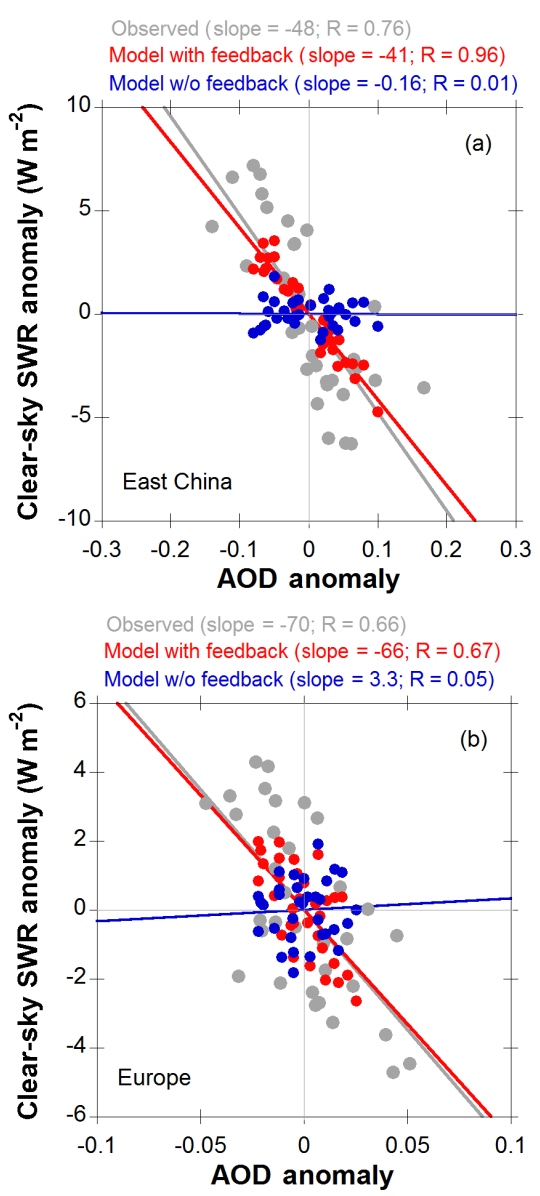

Observed ( slope $=-79 ; \mathrm{R}=0.68$ ) Model with feedback (slope $=-32 ; R=0.54$ ) Model w/o feedback (slope $=15 ; \mathrm{R}=0.26$ )

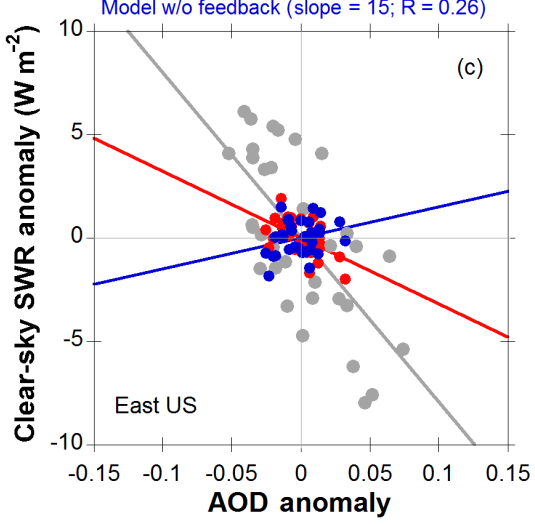

Figure 16. Relationship between regional and monthly average (only summer months) changes in aerosol optical depth and changes in clear-sky surface shortwave radiation during the 2001-2010 period for (a) eastern China, (b) Europe, and (c) the eastern United States. Observed values are shown in grey, CMAQ calculations with direct aerosol radiative feedbacks in red, and CMAQ calculations without aerosol radiative feedbacks in blue. Also indicated are the slope and correlation coefficient $(R)$ for the individual linear regressions. For each data set (model or observed) there are 33 values, corresponding to each summer month over the 11-year (2001-2010) period. The anomaly is estimated by subtracting the corresponding 11-year average for that month. comparison clearly suggests that as tropospheric aerosol burden increases, scattering and absorption reduces the amount of surface SWR. The magnitude of these changes is comparatively larger for eastern China than for Europe and the eastern United States due to the higher levels of tropospheric particulate matter in eastern China. In all three regions, the model simulation without direct aerosol feedback fails to capture the changes in SWR and its association with AOD. In contrast the model simulation incorporating the aerosol direct radiative effects replicates the relationship between the observed AOD and SWR changes during the 2000-2010 period in all three regions as reflected by the higher $R^{2}$ and slopes of the linear regression closer to those inferred from the observed data. These results suggest that the hemispheric two-way coupled WRF-CMAQ configuration can represent the differing regional changes in surface SWR with contrasting changes in regional aerosol burden. Accordingly, this tool could also be used to examine chemistry-climate interactions on hemispheric to regional scales.

\section{Summary and concluding remarks}

The applicability of the CMAQ modeling system was extended to the entire Northern Hemisphere to enable consistent examination of interactions between atmospheric processes occurring on various spatial and temporal scales. Improvements were made in model process representation (stratospheric $\mathrm{O}_{3}$ influences, representation of $\mathrm{NO}_{x}$ recycling through organic nitrates, halogen chemistry in marine environments, deposition over water), structure (model vertical extent and layer resolution), and input data sets (allocation of global emission estimates). These improvements to CMAQ were investigated and evaluated through comparison of model predictions with measurements from surface, aloft, remote sensing, and specialized field campaign platforms. Comparisons with measurements from the INTEXB field campaign indicate that hemispheric CMAQ captures the mean variability in $\mathrm{O}_{3}$ and $\mathrm{SO}_{4}^{2-}$ distributions observed over the tropical and subarctic Pacific regions and episodic transport of Asian pollution across the Pacific as indicated by comparisons of model and observed $\mathrm{SO}_{4}^{2-}$ along specific flight tracks. The ability to capture the development and evolution of intercontinental transport (i.e., the lofting of pollutants in the source region, multiday transport in the FT and subsequent subsidence and mixing down to the surface in receptor regions) is also demonstrated by evaluating a transatlantic Saharan dust transport event and its contributions to elevated surface $\mathrm{PM}_{2.5}$ in the US Gulf of Mexico region. These results suggest that regional CMAQ applications can now be driven by space- and time-varying lateral boundary conditions derived from consistent hemispheric applications, enabling examination of air quality across the United States in the context of the changing global atmosphere. 
The hemispheric CMAQ model can reproduce historical trends in tropospheric air pollution, as shown by comparing simulated results with surface and remote-sensing observation-derived records during 1990-2010. Trends in modeled tropospheric $\mathrm{NO}_{2}$ vertical column distributions agree with those inferred from GOME and SCIAMACHY retrievals and indicate the contrasting and heterogeneous changes in emissions across the Northern Hemisphere, with increases in rapidly developing regions of Asia and decreases in Europe and North America resulting from implementation of control measures. Additionally, comparisons with observed trends at the US CASTNET monitors indicate that though the model captures the resultant decreasing trends in surface-level air pollution (for $\mathrm{O}_{3}$ and $\mathrm{SO}_{4}^{2-}$ ) in the United States, the current configuration underestimated (by 25-47\%) the magnitude of the trend at some monitoring locations. The underestimation in the magnitude of the trend is however significantly reduced in a nested regional simulation utilizing finer horizontal grid resolution and updated historical regional emissions. The changing emission patterns across the Northern Hemisphere will likely influence future long-range pollutant transport patterns and potentially impact background pollution levels in receptor regions. The hemispheric CMAQ model provides a framework to explore such changing impacts on air pollution exposure. For instance, Wang et al. (2017) estimated trends in $\mathrm{PM}_{2.5}$ premature mortality during 1990-2010 using hemispheric CMAQ predictions and show that correlations between population and $\mathrm{PM}_{2.5}$ have become weaker in Europe and North America due to air pollution controls but stronger in East Asia due to deteriorating air quality.

Analysis of aerosol optical and radiative effects inferred from the two-way coupled WRF-CMAQ applications over the Northern Hemisphere also indicate the association between changing tropospheric aerosol burden and clear-sky surface SWR. In rapidly developing regions such as East Asia, the increasing tropospheric aerosol burden results in greater scattering and absorption by aerosols, and that acts to reduce the amount of clear-sky surface SWR. In contrast, increases in clear-sky surface SWR are noted in regions with declining tropospheric aerosol burden, where emission controls have been more active during that period. The two-way coupled WRF-CMAQ configuration that incorporates direct aerosol radiative effects captures these contrasting observed changes in clear-sky SWR across the Northern Hemisphere during 2000-2010, with brightening in the United States and western Europe and dimming in eastern China. Using these modeling results, Xing et al. (2016b) show that because of reduced atmospheric mixing resulting from direct aerosol feedbacks, air pollutants become more concentrated locally, especially in highly polluted and populated regions. Thus, modulation of air pollution due to direct aerosol effects also translates into an additional human health dividend in regions (e.g., the United States and Europe) with air pollution control measures but a penalty for regions (e.g., East Asia) witnessing rapid deterioration in air quality.

Analysis of three-dimensional $\mathrm{O}_{3}$ distributions across the Northern Hemisphere from model sensitivity simulations and comparisons with surface and aloft measurements also highlights the need to better quantify the contribution of STE processes on surface $\mathrm{O}_{3}$. A nontrivial contribution of up to $\sim 10 \mathrm{ppb}$ from the stratosphere to seasonal mean surfacelevel $\mathrm{O}_{3}$ mixing ratios is inferred from the current applications. An accurate characterization of this contribution is essential for source attribution of background $\mathrm{O}_{3}$. Since measurements of 3-D O $\mathrm{O}_{3}$ distributions alone are insufficient to directly quantify this contribution, model estimates need to be better constrained. To that end, additional CMAQ simulations that explore the sensitivity of STE process representation to model vertical extent and vertical grid resolution are warranted. Model calculations presented here also indicate the possible influence of horizontal grid resolution on model evaluation results. Hemispheric CMAQ simulations to date have employed a horizontal grid resolution of $108 \mathrm{~km}$, which is insufficient to resolve local gradients. Emerging environmental problems will likely require the simultaneous characterization of air pollution on local to global scales. Variable-resolution nonuniform grids can simultaneously and accurately resolve local gradients and large-scale features in air pollutant distributions (e.g., Odman and Russell, 1991; Mathur et al., 1992; Srivastava et al., 2000). The emergence of variable-resolution atmospheric dynamical models (e.g., Skamarock et al., 2012) provides opportunities to develop comprehensive atmospheric modeling systems that seamlessly represent the scale interactions on urban to global scales. The use of such approaches could improve the representation of scale interactions in air pollution modeling.

Several efforts are underway to harmonize regional emission estimates and incorporate them into global emission inventories with improved spatial and temporal resolution (e.g., Janssens-Maenhout et al., 2015). It can be expected that future improvements in the performance of hemispheric CMAQ will also be realized through improvements in these underlying global emission inventories used to drive model calculations. Additional improvements in sectorspecific emissions and additional details on chemical speciation of the emissions will also lend themselves to the use of more detailed chemical mechanisms such as RACM2, which explicitly treat the chemistry of longer-lived species (e.g., acetone) that are important for the chemistry of the upper troposphere, and help further assess the relative benefits of the use of different chemical mechanisms on hemispheric scales. Predictions of a variety of atmospheric pollutant species from hemispheric CMAQ are also being compared to those from other modeling systems (Hogrefe et al., 2015) through the activities of Air Quality Model Evaluation International Initiative (AQMEII). The adequacies and inadequacies of the lateral boundary conditions derived from hemispheric CMAQ 
to drive regional CMAQ simulations are being further analyzed through comparisons with those from other large-scale models and observations (Hogrefe et al., 2017) and will also guide the future evolution of the hemispheric CMAQ.

Code availability. Source code for the Community Multiscale Air Quality (CMAQ) modeling system can be downloaded from https: //www.epa.gov/cmaq.

Data availability. Data used to generate figures and tables shown in this article can be downloaded at https://edg.epa.gov/metadata/ catalog/main/home.page. Raw model outputs are available from the corresponding author on request. Observational data sets used in the analyses presented in this paper are available from their respective websites: https://www.epa.gov/aqs (AQS); https://www.epa. gov/castnet (CASTNET); http://www.woudc.org (WOUDC); https: //www-air.larc.nasa.gov/missions/intex-b/dataaccess.htm (INTEXB); https://tropo.gsfc.nasa.gov/intexb/ions06.html (IONS).

Competing interests. The authors declare that they have no conflict of interest.

Disclaimer. The views expressed in this paper are those of the authors and do not necessarily represent the views or policies of the US Environmental Protection Agency.

Special issue statement. This article is part of the special issue "Global and regional assessment of the intercontinental transport of air pollution: results from HTAP, AQMEII and MICS". It is not associated with a conference.

Acknowledgements. We gratefully acknowledge the free availability and use of observational data sets from the INTEX-B field study, CASTNET, AQS, IONS, and WOUDC; remote sensing retrievals from GOME, SCIAMACHY, MODIS, and CERES; and global emission inventories from EDGAR, GEIA, and ARCTAS. We thank Havala Pye and Barron Henderson for comments and suggestions on the initial version of this paper.

Edited by: Stefano Galmarini

Reviewed by: two anonymous referees

\section{References}

Andreae, M. O., Berresheim, H., Andreae, T. W., Kritz, M. A., Bates, T. S., and Merrill, J. T.: Vertical distribution of dimethylsulfide, sulfur dioxide, aerosol ions, and radon over the NorthEast Pacific Ocean, J. Atmos. Chem., 6, 149-173, 1988.

Appel, K. W., Napelenok, S. L., Foley, K. M., Pye, H. O. T., Hogrefe, C., Luecken, D. J., Bash, J. O., Roselle, S. J., Pleim, J. E., Foroutan, H., Hutzell, W. T., Pouliot, G. A.,
Sarwar, G., Fahey, K. M., Gantt, B., Gilliam, R. C., Heath, N. K., Kang, D., Mathur, R., Schwede, D. B., Spero, T. L., Wong, D. C., and Young, J. O.: Description and evaluation of the Community Multiscale Air Quality (CMAQ) modeling system version 5.1, Geosci. Model Dev., 10, 1703-1732, https://doi.org/10.5194/gmd-10-1703-2017, 2017.

Barrie, L. A., Li, S.-M., Toom, D. L., Landsberger, S., and Sturges, W.: Lower tropospheric measurements of halogens, nitrates, and sulphur oxides during Polar Sunrise Experiment 1992, J. Geophys. Res.-Atmos., 99, 25453-25467, 1994.

Bohren, C. F. and Huffman, D. R.: Absorption and Scattering of Light by Small Particles, Wiley-Interscience, New York, USA, 530 pp., 1983.

Brandt, J., Silver, J. D., Frohn, L. M., Geels, C., Gross, A., Hansen, A. B., Hansen, K. M., Hedegaard, G. B., Skoth, C. A., Villadsen, H., Zare, A., and Christensen, J. H.: An integrated model study for Europe and North America using the Danish Eulerian Hemispheric Model with focus on intercontinental transport of air pollution, Atmos. Environ., 53, 156-176, https://doi.org/10.1016/j.atmosenv.2012.01.011, 2012.

Byun, D. W. and Ching, J. K. S.: Science Algorithms of the EPA Models-3 Community Multiscale Air Quality (CMAQ) Modeling System, EPA/600/R-99/030, US Environ. Prot. Agency, Washington, D. C., USA, 1999.

Byun, D. W. and Schere, K. L.: Review of the governing equations, computational algorithms, and other components of the Models3 Community Multiscale Air Quality (CMAQ) modeling system, Appl. Mech. Rev., 59, 51-77, 2006.

Carmichael, G. R., Uno, I., Phadnis, M. J., Zhang, Y., and Sunwoo, Y.: Tropospheric ozone production and transport in the springtime in east Asia, J. Geophys. Res.-Atmos., 103, 10649$10671,1998$.

Danielsen, E. F.: Stratospheric-tropospheric exchange based on radioactivity, ozone and potential vorticity, J. Atmos. Sci., 25, 502518, 1968.

Ebel, A., Haus, H., Jakobs, H. J., Laube, M., Memmesheimer, M., and Oberreuter, A.: Simulation of ozone intrusion caused by a tropopause fold and cut-off low, Atmos. Environ., 25, 21312144, 1991.

Elbern, H., Hendricks, J., and Ebel, A.: A climatology of tropopause folds by global analyses, Theor. Appl. Climatol., 59, 181-200, 1998.

European Commission: Joint Research Centre (JRC)/Netherlands Environmental Assessment Agency, Emission Database for Global Atmospheric Research (EDGAR), release version 4.2., available at: http://edgar.jrc.ec.europa.eu (last access: 25 September 2014), 2011.

Eyth, A., Pouliot, G., Vukovich, J., Strum, M., Dolwick, P., Allen, C., Beidler, J., and Baek, B. H.: Development of 2011 hemispheric emissions for CMAQ, presented at the 2016 CMAS Conference, available at: https://www.cmascenter.org/conference//2016/slides/eyth_ development_hemispheric_2016.pptx, last access: 23 December 2016.

Fiore, A. M., Dentener, F. J., Wild, O., Cuvelier, C., Schultz, M. G., Hess, P., Textor, C., Schulz, M., Doherty, R. M., Horowitz, L. W., MacKenzie, I. A., Sanderson, M. G., Shindell, D. T., Stevenson, D. S., Szopa, S., Dingenen, R. V., Zeng, G., Atherton, C., Bergmann, D., Bey, I., Carmichael, G., Collins, W. J., 
Duncan, B. N., Faluvegi, G., Folberth, G., Gauss, M., Gong, S., Hauglustaine, D., Holloway, T., Isaksen, I. S. A., Jacob, D. J., Jonson, J. E., Kaminski, J. W., Keating, T. J., Lupu, A., Marmer, E., Montanaro, V., Park, R., Pitari, G., Pringle, K. J., Pyle, J. A., Schroeder, S., Vivanco, M. G., Wind, P., Wojcik, G., Wu, S., and Zuber, A.: Multi-model estimates of intercontinental source-receptor relationships for ozone pollution, J. Geophys. Res.-Atmos., 114, D04301, https://doi.org/10.1029/2008JD010816, 2009.

Fishman, J., Fakhruzzaman, K., Croes, B., and Ngana, D.: Identification of widespread pollution in the Southern Hemisphere deduced from satellite analyses, Science, 252, 1693-1696, 1991.

Flemming, J., Huijnen, V., Arteta, J., Bechtold, P., Beljaars, A., Blechschmidt, A.-M., Diamantakis, M., Engelen, R. J., Gaudel, A., Inness, A., Jones, L., Josse, B., Katragkou, E., Marecal, V., Peuch, V.-H., Richter, A., Schultz, M. G., Stein, O., and Tsikerdekis, A.: Tropospheric chemistry in the Integrated Forecasting System of ECMWF, Geosci. Model Dev., 8, 975-1003, https://doi.org/10.5194/gmd-8-975-2015, 2015.

Foley, K. M., Roselle, S. J., Appel, K. W., Bhave, P. V., Pleim, J. E., Otte, T. L., Mathur, R., Sarwar, G., Young, J. O., Gilliam, R. C., Nolte, C. G., Kelly, J. T., Gilliland, A. B., and Bash, J. O.: Incremental testing of the Community Multiscale Air Quality (CMAQ) modeling system version 4.7, Geosci. Model Dev., 3, 205-226, https://doi.org/10.5194/gmd-3-205-2010, 2010.

Foroutan, H., Young, J., Napelenok, S., Ran, L., Appel, K. W., and Pleim, J. E.: Development and evaluation of a physicsbased windblown dust emission scheme implemented in the CMAQ modeling system, J. Adv. Model. Earth Sys., 9, 585-608, https://doi.org/10.1002/2016MS000823, 2017.

Fu, X., Wang, S. X., Cheng, Z., Xing, J., Zhao, B., Wang, J. D., and Hao, J. M.: Source, transport and impacts of a heavy dust event in the Yangtze River Delta, China, in 2011, Atmos. Chem. Phys., 14, 1239-1254, https://doi.org/10.5194/acp14-1239-2014, 2014.

Gan, C.-M., Pleim, J., Mathur, R., Hogrefe, C., Long, C. N., Xing, J., Wong, D., Gilliam, R., and Wei, C.: Assessment of longterm WRF-CMAQ simulations for understanding direct aerosol effects on radiation "brightening" in the United States, Atmos. Chem. Phys., 15, 12193-12209, https://doi.org/10.5194/acp-1512193-2015, 2015a.

Gan, C. M., Hogrefe, C., Mathur, R., Pleim, J., Xing, J., Wong, D., Gilliam, R., Pouliot, G., and Wei, C.: Assessment of the aerosol optics component of the coupled WRF-CMAQ model using CARES field campaign data and s single column model, Atmos. Environ., 115, 670-682, 2015b.

Gillette, D. A., Adams, J., Endo, A., Smith, D., and Kihl, R.: Threshold velocities for input of soil particles into the air by desert soils, J. Geophys. Res.-Oceans, 85, 5621-5630, 1980.

Goliff, W. S., Stockwell, W. R., and Lawson, C. V.: The Regional Atmospheric Chemistry Mechanism, Version 2, Atmos. Environ., 68, 174-185, 2013.

Guenther, A., Hewitt, C. N., Erickson, D., Fall, R., Geron, C., Graedel, T., Harley, P., Klinger, L., Lerdau, M., McKay, W. A., Pierce, T., Scholes, B., Steinbrecher, R., Tallamraju, R., Taylor, J., and Zimmerman, P.: A Global Model of Natural Volatile Organic Compound Emissions, J. Geophys. Res., 100, 8873-8892, 1995.
Hogrefe, C., Xing, J., Flemming, J., Pouliot, G., Roselle, S., and Mathur, R.: Evaluation and Intercomparison of 2010 Hemispheric CMAQ Simulations Performed in the Context of AQMEII and HTAP, presented at the 2015 CMAS Conference, available at: https://www.cmascenter.org/conference//2015/ slides/1300_Christian_Hogrefe_AQMEII_HTAP_2015.pptx (last access: 27 December 2016), 2015.

Hogrefe, C., Liu, P., Pouliot, G., Mathur, R., Roselle, S., Flemming, J., Lin, M., and Park, R. J.: Impacts of Different Characterizations of Large-Scale Background on Simulated Regional-Scale Ozone Over the Continental United States, Atmos. Chem. Phys Discuss., https://doi.org/10.5194/acp-2017-676, in review, 2017.

HTAP: Hemispheric Transport of Air Pollution 2010, Part A: Ozone and Particulate Matter, edited by: Dentener, F., Keating, T., and Akimoto, H., UN Economic Commission for Europe, Air Pollution Studies No. 17, available at: http://www.htap.org (last access: 27 December 2016), 2010.

Husar, R. B.: Intercontinental transport of dust: historical and recent observational evidence, in: Intercontinental Transport of Air Pollution, Handbook of Environmental Chemistry, edited by: Stohl, A., vol. 4, Springer-Verlag, Berlin, https://doi.org/10.1007/b94531, 277-294, 2004.

Iacono, M. J., Delamere, J. S., Mlawer, E. J., Shephard, M. W., Clough, S. A., and Collins, W. D.: Radiative forcing by long-lived greenhouse gases: calculations with the AER radiative transfer models, J. Geophys. Res.-Atmos., 113, D13103, https://doi.org/10.1029/2008JD009944, 2008.

Jacob, D. J., Prather, M. J., Wofsy, S. C., and McElroy, M. B.: Atmospheric distribution of ${ }^{85} \mathrm{Kr}$ simulated with a general circulation model, J. Geophys. Res.-Oceans, 92, 6614-6626, 1987.

Jacob, D. J., Logan, J. A., and Murti, P. P.: Effect of rising Asian emissions on surface ozone in the United States, Geophys. Res. Lett., 26, 2175-2178, 1999.

Jaffe, D., Anderson, T., Covert, D., Kotchenruther, R., Trost, B., Danielson, J., Simpson, W., Bernsten, T., Karlsdottir, S., Blake, D., Harris, J., Carmichael, G., and Uno, I.: Transport of Asian air pollution to North America, Geophys. Res. Lett., 26, 711-714, https://doi.org/10.1029/1999GL900100, 1999.

Janssens-Maenhout, G., Dentener, F., Van Aardenne, J., Monni, S., Pagliari, V., Orlandini, L., Klimont, Z., Kurokawa, J., Akimoto, H., Ohara, T., Wankmueller, R., Battye, B., Grano, D., Zuber, A., and Keating, T.: EDGAR-HTAP: a Harmonized Gridded Air Pollution Emission Dataset Based on National Inventories, European Commission Publications Office, Ispra, Italy, EUR Report No EUR 25229, 2012.

Janssens-Maenhout, G., Crippa, M., Guizzardi, D., Dentener, F., Muntean, M., Pouliot, G., Keating, T., Zhang, Q., Kurokawa, J., Wankmüller, R., Denier van der Gon, H., Kuenen, J. J. P., Klimont, Z., Frost, G., Darras, S., Koffi, B., and Li, M.: HTAP_v2.2: a mosaic of regional and global emission grid maps for 2008 and 2010 to study hemispheric transport of air pollution, Atmos. Chem. Phys., 15, 11411-11432, https://doi.org/10.5194/acp-15-11411-2015, 2015.

Kalnay, E., Kanamitsu, M., Kistler, R., Collins, W., Deaven, D., Gandin, L., Iredell, M., Saha, S., White, G., Woollen, J., Zhu, Y., Chelliah, M., Ebisuzaki, W., Higgins, W., Janowiak, J., Mo, K. C., Ropelewski, C., Wang, J., Leetmaa, A., Reynolds, R., Jenne, R., and Joseph, D.: The NCEP/NCAR 40-year reanalysis project, B. Am. Meteorol. Soc., 77, 437-471, 1996. 
Kasibhatla, P., Chameides, W. L., Duncan, B., Houyoux, M., Jang, C., Mathur, R., Odman, T., and Xiu, A.: Impact of inert organic nitrate formation on ground-level ozone in a regional air quality model using the Carbon Bond Mechanism 4, Geophys. Res. Lett., 24, 3205-3208, https://doi.org/10.1029/97GL03260, 1997.

Kato, S., Loeb, N. G., Rose, F. G., Doelling, D. R., Rutan, D. A., Caldwell, T. E., Yu, L., and Weller, R. A.: Surface irradiances consistent with CERES-derived top-of-atmosphere shortwave and longwave irradiances, J. Climate, 26, 2719-2740, https://doi.org/10.1175/JCLI-D-12-00436.1, 2013.

Kelly, J. T., Bhave, P. V., Nolte, C. G., Shankar, U., and Foley, K. M.: Simulating emission and chemical evolution of coarse sea-salt particles in the Community Multiscale Air Quality (CMAQ) model, Geosci. Model Dev., 3, 257-273, https://doi.org/10.5194/gmd-3-257-2010, 2010.

Li, W. Y., Shen, Z. B., Lu, S. H., and Li, Y. H.: Sensitivity tests of factors influencing wind erosion, J. Desert Res., 27, 984-993, 2007.

Mailler, S., Menut, L., Khvorostyanov, D., Valari, M., Couvidat, F., Siour, G., Turquety, S., Briant, R., Tuccella, P., Bessagnet, B., Colette, A., Létinois, L., Markakis, K., and Meleux, F.: CHIMERE-2017: from urban to hemispheric chemistrytransport modeling, Geosci. Model Dev., 10, 2397-2423, https://doi.org/10.5194/gmd-10-2397-2017, 2017.

Mathur, R., Peters, L. K., and Saylor, R. D.: Sub-grid representation of emission source clusters in regional air quality modeling, Atmos. Environ., 26, 3219-3238, https://doi.org/10.1016/09601686(92)90478-4, 1992.

Mathur, R., Shankar, U., Hanna, A. F., Odman, M. T., McHenry, J. N., Coats, C. J., Alapaty, K., Xiu, A., Arunachalam, S., Olerud, D. T., Byun, D. W., Schere, K. L., Binkowski, F. S., Ching, J. K. S., Dennis, R. L., Pierce, T. E., Pleim, J. E., Roselle, S. J., and Young, J. O.: Multiscale air quality simulation platform (MAQSIP): initial applications and performance for tropospheric ozone and particulate matter, J. Geophys. Res.-Atmos., 110, D13308, https://doi.org/10.1029/2004JD004918, 2005.

Mathur, R., Lin, H. M., McKeen, S., Kang, D., and Wong, D.: Three-Dimensional Model Studies of Exchange Processes in the Troposphere: Use of Potential Vorticity to Specify Aloft $\mathrm{O}_{3}$ in Regional Models, presented at the 7th Annual CMAS Conference, available at: https://www.cmascenter.org/conference/2008/ slides/mathur_three-dimension_model_cmas08.ppt (last access: 27 December 2016), 2008.

Mathur, R., Pleim, J., Wong, D., Otte, T., Gilliam, R., Roselle, S., Young, J., Binkowski, F., and Xiu, A.: The WRF-CMAQ Integrated On-line Modeling System: Development, Testing, and Initial Applications, Air Pollution Modeling and its Application XX, edited by: Steyn, D. G., Rao, S. T., Springer, Dordrecht, the Netherlands, 155-159, 2010.

Mathur, R., Roselle, S., Young, J., and Kang, D.: Representing the effects of long-range transport and lateral boundary conditions in regional air pollution models, in: Air Pollution Modeling and its Application XXII, edited by: Steyn, D., Builtjes, P., and Timmermans, R., Chapt. 51, Springer, Dordrecht, https://doi.org/10.1007/978-94-007-5577-2_51, 303-308, 2014.

McCaffery, S. J., McKeen, S. A., Hsie, E.-Y., Parrish, D. D., Cooper, O. R., Holloway, J. S., Hübler, G., Fehsenfeld, F. C., and Trainer, M.: A case study of stratosphere- troposphere exchange during the 1996 North Atlantic Regional Experiment, J. Geophys. Res.-Atmos., 109, D14103, https://doi.org/10.1029/2003JD004007, 2004.

NRC: Global sources of local pollution: an assessment of long-range transport of key air pollutants to and from the United States, National Academy Press, Washington, DC, USA, https://doi.org/10.17226/12743, 2009.

Odman, M. T. and Russell, A. G.: Multiscale modeling of pollutant transport and chemistry, J. Geophys. Res.-Atmos., 96, 73637370, 1991.

Pleim, J. E.: A Combined Local and Nonlocal Closure Model for the Atmospheric Boundary Layer. Part I: Model Description and Testing, J. Appl. Meteor. Clim.,46, 1383-1395, https://doi.org/10.1175/JAM2539.1, 2007.

Pleim, J. E. and Gilliam, R.: An indirect data assimilation scheme for deep soil temperature in the Pleim-Xiu land surface model, J. Appl. Meteorol. Clim., 48, 1362-1376, 2009.

Price, C., Penner, J., and Prather, M.: $\mathrm{NO}_{x}$ from lightning: 1. Global distribution based on lightning physics, J. Geophys. Res.-Atmos., 102, 5929-5941, 1997.

Prospero, J. M. and Carlson, T. N.: Vertical and areal distribution of Saharan dust over the western equatorial North Atlantic Ocean, J. Geophys. Res.-Oc. Atm., 77, 5255-5265, 1972.

Read, K. A., Mahajan, A. S., Carpenter, L. J., Evans, M. J., Faria, B. V. E., Heard, D. E., Hopkins, J. R., Lee, J. D., Moller, S. J., Lewis, A. C., Mendes, L., McQuaid, J. B., Oetjen, H., Saiz-Lopez, A., Pilling, M. J., and Plane, J. M. C.: Extensive halogen mediated ozone destruction over the tropical Atlantic Ocean, Nature, 453, 1232-1235, 2008.

Richter, A., Burrows, J. P., Nüß, H., Granier, C., and Niemeier, U.: Increase in tropospheric nitrogen dioxide over China observed from space, Nature, 437, 129-132, https://doi.org/10.1038/nature04092, 2005.

Roelofs, G. J. and Lelieveld, J.: Model study of the influence of cross-tropopause $\mathrm{O}_{3}$ transports on tropospheric $\mathrm{O}_{3}$ levels, Tellus B, 49, 38-55, 1997.

Sarwar, G., Appel, K. W., Carlton, A. G., Mathur, R., Schere, K., Zhang, R., and Majeed, M. A.: Impact of a new condensed toluene mechanism on air quality model predictions in the US, Geosci. Model Dev., 4, 183-193, https://doi.org/10.5194/gmd-4183-2011, 2011.

Sarwar, G., Simon, H., Bhave, P., and Yarwood, G.: Examining the impact of heterogeneous nitryl chloride production on air quality across the United States, Atmos. Chem. Phys., 12, 6455-6473, https://doi.org/10.5194/acp-12-6455-2012, 2012.

Sarwar, G., Godowitch, J., Henderson, B. H., Fahey, K., Pouliot, G., Hutzell, W. T., Mathur, R., Kang, D., Goliff, W. S., and Stockwell, W. R.: A comparison of atmospheric composition using the Carbon Bond and Regional Atmospheric Chemistry Mechanisms, Atmos. Chem. Phys., 13, 9695-9712, https://doi.org/10.5194/acp-13-9695-2013, 2013.

Sarwar, G., Simon, H., Xing, J., and Mathur, R.: Importance of tropospheric $\mathrm{ClNO}_{2}$ chemistry across the Northern Hemisphere, Geophys. Res. Lett., 41, 4050-4058, https://doi.org/10.1002/2014GL059962, 2014.

Sarwar, G., Gantt, B., Schwede, D., Foley, K., Mathur, R., and Saiz-Lopez, A.: Impact of enhanced ozone deposition and halogen chemistry on tropospheric ozone over the 
Northern Hemisphere, Environ. Sci. Technol., 49, 9203-9211, https://doi.org/10.1021/acs.est.5b01657, 2015.

Schere, K. L., Flemming, J., Vautard, R., Chemel, C., Colette, A., Hogrefe, C., Bassagnet, B., Meleux, F., Mathur, R., Roselle, S. J., Hu, R., Sokhi, R., Rao, S. T., and Galmarina, S.: Trace gas/aerosol boundary concentrations and their impacts on continental-scale AQMEII modelling domains, Atmos. Environ., 53, 38-50, 2012.

Schwede, D., Luecken, D., Walker, J., Pouliot, G., Appel, W., Kelly, J., and Baker, K.: Improvements to the Characterization of Organic Nitrogen Chemistry and Deposition in CMAQ, presented at the 2014 CMAS Conference, available at: https://www.cmascenter.org/conference//2014/slides/donna_ schwede_improvements_treatment_2014.pptx (last access: 29 December 2016), 2014.

Shepson, P. B., Mackay, E., and Muthuramu, K.: Henry's Law constants and removal processes for several atmospheric $\beta$ hydroxy alkyl nitrates, Environ. Sci. Technol., 30, 3618-3623, https://doi.org/10.1021/es960538y, 1996.

Singh, H. B., Brune, W. H., Crawford, J. H., Flocke, F., and Jacob, D. J.: Chemistry and transport of pollution over the Gulf of Mexico and the Pacific: spring 2006 INTEX-B campaign overview and first results, Atmos. Chem. Phys., 9, 2301-2318, https://doi.org/10.5194/acp-9-2301-2009, 2009.

Skamarock, W. C., Klemp, J. B., Duda, M. G., Fowler, L. D., and Park, S.-H.: A multiscale nonhydrostatic atmospheric model using centroidal Voronoi tessellations and C-grid staggering, Mon. Weather Rev., 140, 3090-3105, https://doi.org/10.1175/MWRD-11-00215.1, 2012

Srivastava, R. K., McRae, D. S., and Odman, M. T.: An adaptive grid algorithm for air-quality modeling, J. Comput. Phys., 165, 437-472, https://doi.org/10.1006/jcph.2000.6620, 2000.

Streets, D. G., Yan, F., Chin, M., Diehl, T., Mahowald, N., Schultz, M., Wild, M., Wu, Y., and Yu, C.: Anthropogenic and natural contributions to regional trends in aerosol optical depth, J. Geophys. Res.-Atmos., 114, D00D18, https://doi.org/10.1029/2008JD011624, 2009.

Tang, Y., Lee, P., Tsidulko, M., Huang, H.-C., McQueen, J. T., DiMego, G. J., Emmons, L. K., Pierce, R. B., Thompson, A. M., Lin, H.-M., Kang, D., Tong, D., Yu, S., Mathur, R., Pleim, J. E., Otte, T. L., Pouliot, G., Young, J. O., Schere, K. L., Davidson, P. M., and Stajner, I.: The impacts of chemical lateral boundary conditions on CMAQ predictions of tropospheric ozone over the Continental United States, Environ. Fluid Mech., 9, 43-58, https://doi.org/10.1007/s10652-008-9092-5, 2008.

Tong, D., Mathur, R., Mobley, D., Wong, D. C., Lin, H., Yu, S., and Chai, T.: CMAQ Dust Module: Development and Initial Applications, presented at 2008 Annual CMAS Conference, available at: https://www.cmascenter.org/conference/2008/ slides/tong_cmaq_dust_cmas08.ppt (last access: 29 December 2016), 2008.

Treves, K. and Rudich, Y.: The atmospheric fate of $\mathrm{C}_{3}-\mathrm{C}_{6}$ hydroxyalkyl nitrates, J. Phys. Chem. A, 107, 7809-7817, https://doi.org/10.1021/jp0350641, 2003.

Uno, I, Eguchi, K., Yumimoto, K., Takemura, T., Shimizu, A., Uematsu, M., Liu, Z., Wang, Z., Hara, Y., and Sugimoto, N.: Asian dust transported one full circuit around the globe, Nat. Geosci., 2, 557-560, https://doi.org/10.1038/ngeo583, 2009. van $\operatorname{der}$ A, R. J., Eskes, H. J., Boersma, K. F., van Noije, T. P. C., Van Roozendael, M., De Smedt, I., Peters, D. H. M. U., and Meijer, E. W.: Trends, seasonal variability and dominant $\mathrm{NO}_{x}$ source derived from a ten year record of $\mathrm{NO}_{2}$ measured from space, J. Geophys. Res.-Atmos., 113, D04302, https://doi.org/10.1029/2007JD009021, 2008.

van Donkelaar, A., Martin, R. V., Leaitch, W. R., Macdonald, A. M., Walker, T. W., Streets, D. G., Zhang, Q., Dunlea, E. J., Jimenez, J. L., Dibb, J. E., Huey, L. G., Weber, R., and Andreae, M. O.: Analysis of aircraft and satellite measurements from the Intercontinental Chemical Transport Experiment (INTEX-B) to quantify long-range transport of East Asian sulfur to Canada, Atmos. Chem. Phys., 8, 2999-3014, https://doi.org/10.5194/acp-8-29992008, 2008.

Vogt, R., Sander, R., Glasow, R. V., and Crutzen, P. J.: Iodine chemistry and its role in halogen activation and ozone loss in the marine boundary layer: a model study, J. Atmos. Chem., 32, 375395, 1999.

Wang, K.-Y., Shallcross, D. E., and Pyle, J. A.: Seasonal variations and vertical movement of the tropopause in the UTLS region, Ann. Geophys., 20, 871-874, https://doi.org/10.5194/angeo-20871-2002, 2002.

Wang, J., Xing, J., Mathur, R., Pleim, J., Wang, S., Hogrefe, C., Gan, C.-M., Wong, D., and Hao, J.: Historical trends in $\mathrm{PM}_{2.5}$ related premature mortality during 1990-2010 across the Northern Hemisphere, Environ. Health Persp., 125, 400-408, https://doi.org/10.1289/EHP298, 2017.

Wild, M.: Global dimming and brightening: a review, J. Geophys. Res.-Atmos., 114, D00D16, https://doi.org/10.1029/2008JD011470, 2009.

Wild, M., Folini, D., Schär, C., Loeb, N., Dutton, E. G., and KönigLanglo, G.: The global energy balance from a surface perspective, Clim. Dynam., 40, 3107-3134, 2013.

Wielicki, B. A., Barkstrom, B. R., Baum, B. A., Charlock, T. P., Green, R. N., Kratz, D. P., Lee, R. B., Minnis, P., Smith, G. L., Wong, T., Young, D. F., Cess, R. D., Coakley, J. A., Crommelynck, D. A. H., Donner, L., Kandel, R., King, M. D., Miller, A. J., Ramanathan, V., Randall, D. A., Stowe, L. L., and Welch, R. M.: Clouds and the Earth's Radiant Energy System (CERES): algorithm overview, IEEE T. Geosci. Remote, 36, 1127-1141, 1998.

Wong, D. C., Pleim, J., Mathur, R., Binkowski, F., Otte, T., Gilliam, R., Pouliot, G., Xiu, A., Young, J. O., and Kang, D.: WRFCMAQ two-way coupled system with aerosol feedback: software development and preliminary results, Geosci. Model Dev., 5, 299-312, https://doi.org/10.5194/gmd-5-299-2012, 2012.

Xie, Y., Paulot, F., Carter, W. P. L., Nolte, C. G., Luecken, D. J., Hutzell, W. T., Wennberg, P. O., Cohen, R. C., and Pinder, R. W.: Understanding the impact of recent advances in isoprene photooxidation on simulations of regional air quality, Atmos. Chem. Phys., 13, 8439-8455, https://doi.org/10.5194/acp13-8439-2013, 2013.

Xing, J., Pleim, J., Mathur, R., Pouliot, G., Hogrefe, C., Gan, C.-M., and Wei, C.: Historical gaseous and primary aerosol emissions in the United States from 1990 to 2010, Atmos. Chem. Phys., 13, 7531-7549, https://doi.org/10.5194/acp-13-7531-2013, 2013.

Xing, J., Mathur, R., Pleim, J., Hogrefe, C., Gan, C.-M., Wong, D. C., Wei, C., Gilliam, R., and Pouliot, G.: Observations and modeling of air quality trends over 1990-2010 across the North- 
ern Hemisphere: China, the United States and Europe, Atmos. Chem. Phys., 15, 2723-2747, https://doi.org/10.5194/acp-152723-2015, 2015a.

Xing, J., Mathur, R., Pleim, J., Hogrefe, C., Gan, C.-M., Wong, D. C., and Wei, C.: Can a coupled meteorology-chemistry model reproduce the historical trend in aerosol direct radiative effects over the Northern Hemisphere?, Atmos. Chem. Phys., 15, 999710018, https://doi.org/10.5194/acp-15-9997-2015, 2015b.

Xing, J., Mathur, R., Pleim, J., Hogrefe, C., Gan, C.-M., Wong, D., Wei, C., and Wang, J.: Air pollution and climate response to aerosol direct radiative effects: a modeling study of decadal rends across the Northern Hemisphere, J. Geophys. Res.-Atmos., 120, 12221-12236, https://doi.org/10.1002/2015JD023933, 2015c.

Xing, J., Mathur, R., Pleim, J., Hogrefe, C., Wang, J., Gan, C.-M., Sarwar, G., Wong, D. C., and McKeen, S.: Representing the effects of stratosphere-troposphere exchange on 3-D $\mathrm{O}_{3}$ distributions in chemistry transport models using a potential vorticitybased parameterization, Atmos. Chem. Phys., 16, 10865-10877, https://doi.org/10.5194/acp-16-10865-2016, 2016 .
Xing, J., Wang, J., Mathur, R., Pleim, J., Wang, S., Hogrefe, C., Gan, C.-M., Wong, D., and Hao, J.: Unexpected benefits of reducing aerosol cooling effects, Environ. Sci. Technol., 50, 7527 7534, https://doi.org/10.1021/acs.est.6b00767, 2016 b.

Zhang, L., Jacob, D. J., Boersma, K. F., Jaffe, D. A., Olson, J. R., Bowman, K. W., Worden, J. R., Thompson, A. M., Avery, M. A., Cohen, R. C., Dibb, J. E., Flock, F. M., Fuelberg, H. E., Huey, L. G., McMillan, W. W., Singh, H. B., and Weinheimer, A. J.: Transpacific transport of ozone pollution and the effect of recent Asian emission increases on air quality in North America: an integrated analysis using satellite, aircraft, ozonesonde, and surface observations, Atmos. Chem. Phys., 8, 6117-6136, https://doi.org/10.5194/acp-8-6117-2008, 2008. 